Portland State University

PDXScholar

Dissertations and Theses

Dissertations and Theses

Spring 6-3-2015

\title{
Staying on Script: Sexual Scripts and Sex Education
}

Elizabeth Carol Hauck

Portland State University

Follow this and additional works at: https://pdxscholar.library.pdx.edu/open_access_etds

Part of the Gender and Sexuality Commons, and the Health and Physical Education Commons Let us know how access to this document benefits you.

\section{Recommended Citation}

Hauck, Elizabeth Carol, "Staying on Script: Sexual Scripts and Sex Education" (2015). Dissertations and Theses. Paper 2401.

https://doi.org/10.15760/etd.2398

This Thesis is brought to you for free and open access. It has been accepted for inclusion in Dissertations and Theses by an authorized administrator of PDXScholar. For more information, please contact pdxscholar@pdx.edu. 
Staying on Script: Sexual Scripts and Sex Education

by

Elizabeth Carol Hauck

A thesis submitted in partial fulfillment of the requirements for the degree of

Master of Science

in Sociology

Thesis Committee: Maura Kelly, Chair Emily Shafer Lindsey Wilkinson

Portland State University 2015 


\begin{abstract}
Existing research suggests that men and women develop differing sexual scripts that influence their behavior, interactions and emotions regarding sex. The objective for this project is to examine the experiences of men and women with formal sex education programs, especially in regards to information about: anatomy and biology, sexual responsibility and risk taking, sexual desire, virginity and abstinence, as well as to explore sources of sex education outside of school. Several studies suggest masculine sexual scripts dictate that men generally construct a more body-focused approach to sex, with an emphasis on competition, aggression and achievement. Conversely, emphasized feminine sexual scripts call for a more emotion-focused approach to sex that stresses selfcontrol, resistance and sexual 'gatekeeping'. One of the explanations for this is adolescents' experience with formal sex education in school. Gendered messages in sex education that reproduce dominant sexual scripts have the potential to reinforce sexual double standards that affirm male desire and regulate female desire. Previous studies have determined school to be a place where individuals develop scripts that guide them through many aspects of social life. While one recent study has pointed to the existence of gendered messages in sex education films, there is little research on how men's and women's experiences with formal sex education influence their interaction with different sexual scripts.
\end{abstract}

Additionally, this research recognizes that interaction with sexual scripts occurs in a multitude of settings over the life course, and although formal sex education is the focus 
of this analysis because of the explicit messages communicated to adolescents during a very formative stage, other more informal sources of sexual information (i.e. family, peers, and the internet) are explored in comparison with school-based sex education. The findings of this study indicate a gendered patter in access to sexual scripts, drawing from participants' accounts of their sex education experiences in school, as well as important differences in the messages, or scripts communicated to them about sex from friends, family and online. Most notably, men and women generally recount interaction with scripts that reinforce traditional masculine and feminine sexuality in formal, school-based sex education programs. However, sexual learning from more informal sources, like from families and the internet, indicate possible shifts in traditional gendered sexuality, especially for women. 
Dedicated to:

Rob and Janet Hauck

and

Nathan Zetterberg 


\section{TABLE OF CONTENTS}

ABSTRACT I I

LIST OF TABLES V V

CHAPTER 1: INTRODUCTION 1

CHAPTER 2: LITERATURE REVIEW 6

CHAPTER 3: METHODS 27

CHAPTER 4: SEXUAL SCRIPTS AND FORMAL SEX EDUCATION 39

CHAPTER 5: SEXUAL SCRIPTS AND INFORMAL SEX EDUCATION 59

CHAPTER 6: CONCLUSION 95

$\begin{array}{ll}\text { REFERENCES } & 108\end{array}$

APPENDIX: INTERVIEW GUIDE FOR PARTICIPANTS 114 


\section{LIST OF TABLES}

TABLE 1: STUDY PARTICIPANT DATA

TABLE 2: SEXUAL SCRIPT CATEGORIES

TABLE 3: SEXUAL SCRIPTS IN SEX EDUCATION

TABLE 4: SEXUAL SCIPTS IN THE FAMILY

TABLE 5: SEXUAL SCRIPTS IN PEER GROUPS

TABLE 6: SEXUAL SCRIPTS AND THE INTERNET 


\section{CHAPTER 1: INTRODUCTION}

Existing literature suggests that men and women learn, internalize and take up differing sexual scripts that influence their behavior, interactions and emotions regarding sex (Gagnon and Simon 1973; Jackson 2007; Wiederman 2005). Sexual scripts function as guidelines or blueprints for appropriate sexual behavior and experiences, and link these behaviors to meaning. Several studies suggest traditionally masculine sexual scripts dictate that men construct a more body-focused approach to sex, with an emphasis on competition, aggression and achievement, coupled with an apathy toward or a resistance to contraception use (Fagen and Anderson 2012; Haste 1998; Krahe 2007; MatickaTyndale et al. 2005; Sanders 2008; Wiederman 2005). Conversely, traditionally feminine sexual scripts call for a more emotion-focused approach to sex that emphasizes selfcontrol, resistance and sexual gatekeeping (Bowleg, Lucas and Tschann 2004; Carpenter 1998, 2009; Hynie 1998; Maticka-Tyndale et al. 2005; Tolman 2009; Wiederman 2005).

One of the explanations for this is adolescents' experience with formal sex education in school. Previous studies have determined school to be a place where individuals learn scripts that guide them through many aspects of social life (Thorne 2009; Wentzel and Looney 2007). More specifically, interaction with sexual scripts takes place in school, especially through the explicit messages about sex and sexual behavior communicated during formal sex education programs (Hartley and Drew 2002). Gendered messages in sex education that reproduce dominant sexual scripts have the potential to reinforce sexual double standards that affirm male desire and regulate female 
desire (Hartley and Drew 2002; Tolman 2009). While public support for sex education in schools remains in the majority (National Public Radio 2004), the content of formal sex education curricula is a subject of heated debate in both social and political arenas (Carpenter 2009; Luker 2007). Previous research examined the content of sex education curricula (Allen 2006; Fields 2008; Gordon and Ellingson 2006; Kirby 2002; Kirby 2008). These studies have explored the influence that the social and regional context of sex education programs have on content (Fields 2008), the ways that students interpret sex education lessons (Gordon and Ellingson 2006) and the efficacy of different sex education programs in delaying or curbing 'risky' sexual behavior (Kirby 2002, 2008). However, with the exception of one study (Hartley and Drew 2002) that has pointed to the existence of gendered messages in sex education films, there is little research on how men's and women's experiences with school-based sex education shape their interactions with different sexual scripts.

School-based sex education is of course not the only place that adolescents learn about sex, or interact with sexual scripts. Previous research has also explored the more informal sources of sexual learning, like the family, peers, and the internet (Bleakley et al. 2009; Somers and Surmann 2007). In these more informal sex education experiences sexual scripts are also communicated, and gendered messages can be affirmed, reproduced or challenged. For example, previous research on peer group communication about sex finds that adolescent boys use their peers to construct masculine identities by demonstrating exaggerated heterosexual interest and activity (Flood 2008; Pascoe 2007). In contrast, studies focused on sexual learning in the family note that daughters hear much more about sex from their parents than do sons, indicating more exposure to sexual 
scripts in this setting (Epstein and Ward 2008; Nolin and Petersen 1992). Also, exploring the influence that sexual scripts have on sexual learning online may be especially important, as research indicates distinct gendered patterns in the information about sex that is sought out via the internet (Mesch 2009; Ybarra and Mitchell 2005). These informal settings offer a significant comparison to formal, school-based sex education programs. Most importantly, this comparison shows important differences in access to sexual scripts based on gender.

The findings of this study illuminate important aspects of these informal sources, especially for women. Narratives of participants indicate that communication about sex among mothers and daughters is shifting generationally, with mothers being motivated by their own negative experiences with sex education to share information about healthy sexuality and to support their daughters' sexual agencies. In tandem with this shift, participant accounts also highlight the potential of the internet as a source of increased sexual knowledge and sexual agency, especially for women, who can now access more affirming information about sexuality online. These informal sources stand in contrast to female participants experiences with school-based sex education, where they had little access to sexual scripts that were supportive and affirming. These findings reflect sociologist Paula England's argument that the gender revolution is "uneven and stalled", meaning that women's lives have changed much in comparison with men's, who remain reluctant to move into devalued and badly rewarded, traditionally feminine aspects of social life (2010:149).

This project examines the experiences of men and women with school-based sex education programs, especially in regard to information about: anatomy and biology, 
sexual responsibility and risk taking, sexual desire, virginity and abstinence. This project also compares experiences with additional sources of sex education outside of school. While acknowledging that interaction with sexual scripts occurs in a multitude of settings over the life course, school-based sex education is the focus of this analysis because of the explicit messages communicated to adolescents during a very formative stage. In comparison, the experiences of men and women with more informal sources of sexual learning, like the family, peer groups and the internet are also be examined. The research questions addressed in this study are:

1) How do men and women describe the sexual scripts that were communicated to them during formal and informal sex education?

2) How do the sexual scripts communicated in formal (school-based) and informal (i.e. family, peers, and the internet) sex education compare?

3) How does access to these sexual scripts vary by gender?

\section{Overview of Chapters}

Chapter two of this thesis is a review of previous sociological work that informs this study. Important topic areas include: sexual scripting as a theoretical framework put forth by Gagnon and Simon (1973) and its use in subsequent studies of sexuality, an exploration of previous work on traditional masculine sexuality and traditional feminine sexuality, an overview of the most prominent sources of sexual learning like the family, peer groups, the internet and the sex education classroom, and finally, a mention of the few studies that have used the scripting approach to study school-based sex education. In 
chapter three, the method used in data collection and analysis is outlined and discussed, as well as both its strengths and limitations.

Chapters four and five each present important sections of analysis. In chapter four, school-based sex education is addressed and six relevant sexual scripts developed from participants' narratives are introduced. These scripts are discussed in terms of how they were communicated during sex education programs, and how access to them varied by gender. Chapter five explores other, more informal sources of sexual learning like the family and peer groups, in comparison with school-based sex education. The six scripts introduced in chapter four are revisited, and nuances regarding how and to whom they were communicated from these more informal sources are discussed. In chapter six, the final chapter, the findings are revisited, and practical and theoretical implications are offered. 


\section{CHAPTER 2: LITERATURE REVIEW}

\section{Sexual Scripts}

Rooted in a social constructionist approach, Gagnon and Simon's conception of sexual scripts redefined sexual behavior in terms that were fundamentally social (Brickell 2006; Kimmel 2007). In contrast to previously relied-upon essentialist approaches that emphasized the biological origins of sexual behavior, sexual scripting theory describes sexual behavior and its associated meanings as learned within a particular social and cultural context. Gagnon and Simon claimed that nothing was intrinsically sexual, but that sexual meaning could be associated with any behavior or interaction in a particular setting (Kimmel 2007; Parker 2010). They wrote "desire is not reducible to an appetite, a drive, an instinct; it does not create the self, rather it is part of the process of the creation of the self” (Simon and Gagnon 1999:30).

Sexual scripts both offer guidelines for appropriate sexual behavior and experiences, and link these behaviors to meaning. Scripts can be thought of as "blueprints" for sexual conduct; they allow individuals to conceptualize their role in sexual encounters, and serve to decrease anxiety in social interaction by enabling actors to predict and interpret each other's behavior. Scripts shed light on the normative and sequenced behavior in sexual encounters that are usually thought of as romantic and spontaneous (Gagnon and Simon 1973).

From this definition three levels of sexual scripts are outlined: cultural scripts, interpersonal scripts and intrapsychic scripts (Gagnon and Simon 1973). Cultural scripts can be thought of as broad frameworks that orchestrate sexual experience on the 
collective level. Cultural scripts dictate normative sexual behavior, and are often institutional (e.g. marriage laws, formal sex education curriculum) (Wiederman 2005). Interpersonal scripts connect this social framework to the individual experience. These scripts allow the individual to adapt cultural scripts to facilitate sexual exchanges in specific settings (Brickell 2006; Parker 2010). Lastly, intrapsychic scripts refer to internalized norms that influence the ways that individuals interpret and attach meanings to their own sexual experiences, behavior and interactions (Kimmel 2007).

The scripting approach generally has also been used in psychological studies of social behavior and interaction, and it is in this body of literature that the concept of counterscripts is defined. In psychologists Joan Lucariello and Catherine Mindolovich's work on the subject, they postulate that counterscripts are constructed in the event that 'script-deviant' behavior is normalized and assimilated into dominant script organization (2002:92). In studies of sexuality, counterscripts can be used to understand and interpret sexual norms that are developed in contrast or opposition to dominant sexual scripts.

This theoretical model is especially useful in that it illustrates the ways that gender and sexuality are "mutually reinforcing" (Kimmel 2007). Sexual scripts rely heavily on gender for their construction (Gagnon 1990; Jackson 2007). Jackson writes of sexual scripts: "Gagnon and Simon uncoupled gender and sexuality, according temporal priority to gender" (2007:9). Gender is a framework from which sexual scripts can be developed and internalized, and men and women take up different sexual scripts in performance of masculinity and femininity.

Gagnon (1990) illustrates this point by noting that sexuality and gender are linked in different ways in different cultures, at different times in history. Western cultures use 
binary gender to frame sex in cultural sexual scripts (Wiederman 2005). As boys develop into men, they are given access to dominant scripts that prescribe their gendered sexual behavior and experience as body focused and sources of physical pleasure (Wiederman 2005), aggressive (Sanders 2008) and agentic (Fagen and Anderson 2012). Just as gender is believed to be constructed based on difference (Connell and Messerschmidt 2005; DeBeauvoir 1949), dominant sexual scripts made available to men and women are contrasting and complementary. The feminine sexual self is scripted as relational, passive (Wiederman 2005) and "absent of embodied sexual desire" (Tolman 2002:54). Feminine sexual scripts include an emphasis on the dangers of sexual behavior and prescribe sexual control and 'gatekeeping' for women (Wiederman 2005; Gordon and Ellingson 2006).

Although cultural scripts emphasize men's and women's sexual natures as different and complimentary (Wiederman 2005), Gagnon and Simon's theory leaves room for the exercise of human agency, as individuals interact on different levels with the scripts present in their given context (Brickell 2006). However, a violation of dominant sexual scripts can result in confusion and often conflict (Fagen and Anderson 2012; Gagnon 1990). Sociologists Judith Long Laws and Pepper Schwartz (1977) compare sexual scripts to language in their work, a language through which a culture reaffirms its dominant norms. No such script exists for experiences of sexuality that deviate from the norm, and alternative sexual feelings or identities are silenced and denied (Laws and Schwartz 1977).

Access to particular sexual scripts differs based on social location, and characteristics like age, race, and class, along with gender. These dominant sexual scripts also vary according to location and historical context. Empirical work guided by the 
scripting approach has explored the presence and usages of sexual scripts in varying contexts.

Previous research has explored the presence of sexual scripts in media, and concludes that media often communicates sexual scripts in different forms and capacities. Carpenter's studies on the subject explore and illustrate the sexual scripts available in the media directed at adolescents (Carptener 1998; Carpenter 2009). Kelly (2010) determined that sexual scripts portrayed in teen television dramas attached different meanings to virginity and virginity loss.

Several studies illustrate how dominant cultural scripts are mirrored in different contexts and settings. Sanders (2008) explored sexual behavior and intimacy in the context of paid sex work. This study concludes that the sexual scripts taken up by male clients mirror the normative sexual scripts taken up by heterosexual males in dominant culture, exhibiting some of the same frameworks of romance and courtship (Sanders 2008). Maticka-Tyndale et al. (2005) investigated the scripting of sexual encounters among young people in Kenya and found that increased westernization had led to gender differentiated sexual scripts describing boys as forceful initiators and girls as passive recipients of 'sex play' (Maticka-Tyndale et al. 2005). Researchers Lisa Bowleg, Kenya Lucas and Jeanne Tschann (2004) studied the sexual scripts of low-income, African American women and found a relationship between the sexual scripts taken up by their participants and their perceived lack of control of sexual encounters and condom use. Hynie et al.'s (1998) study of male and female undergraduates determined women to take up more relational sexual scripts in comparison with men. 
In contrast, Fagen and Anderson's (2012) study explores a contradiction of cultural sexual scripts. They conducted interviews with 20 men who reported unwanted sexual experiences with women. These men took up gatekeeping sexual scripts in these specific scenarios in response to women's advances. Although gatekeeping is traditionally an aspect of feminine sexuality, the men in Fagen and Anderson's study illustrate their practices of gatekeeping as agentic and ultimately masculine. Lastly, a recent study of men in urban neighborhoods of New York City concluded that the men in the study felt limited by the sexual scripts available to them, and were sometimes uncertain of their utility. The authors suggest that their interviews with men indicate a movement towards new sexual scripts taken up by men that include sex as an aspect of emotional intimacy (Seal and Erhardt 2003).

Previous research has looked at sexual scripts in media and in interviews with young adults about their sexual experiences and understandings. Little research has focused on the transmission of sexual scripts through formal sex education (but see Hartley and Drew 2002). Given that sex education in school occurs at a formative time in adolescent development and includes direct instructions about sexual behavior, this setting is well-suited for research guided by the scripting approach.

\section{Gendered Sexual Scripts}

As was introduced above, one of the most obvious delineations of sexual scripts are those scripts culturally available to men and women (Wiederman 2005). Sexual script theory is especially useful in that it illuminates the process of constructing gender and sexuality simultaneously; for example sociologist Michael Kimmel (2007:71) 
describes the relationship between gender and sexuality as "mutually reinforcing: We construct a sexuality through gender and we confirm gender through sexual behavior". Sexual scripts traditionally taken up by men dictate that men should be sexually active, aggressive and competitive. Culturally, men's social status increases with their number of sexual partners, and these masculine sexual scripts often elicit a resistance to emotional commitment and contraceptive use (Noar and Morokoff 2002; Wiederman 2005). For women, sexuality is scripted in the converse. Women's sexual roles involve defensiveness and gatekeeping, while sexual desire should be suppressed or channeled into a committed relationship (Fallon 2013; Laws and Schwartz 1977). These dominant cultural scripts leave no language to affirm alternative sexual experiences or feelings (Laws and Schwartz 1977; Tolman 2002).

Traditional Masculine Sexuality

Male experiences of sexuality are largely under-researched in comparison with female sexuality, perhaps due to a tendency to conflate the masculine with the norm, and to interpret gendered sexuality as experienced by women (Choo and Feree 2010). However, the body of previous research has theorized that the sexual scripts traditionally taken up by men describe male sexual behavior as active, agentic, aggressive and centered on physical pleasure (Gagnon 1990; Wiederman 2005). Sexual desire is expected and affirmed in men (especially in comparison with women, see Fine 1988; Tolman 2002) and men are culturally encouraged to explore and experience sexuality at their own discretion. 
Research indicates that, as adolescents, sexual feelings for boys are affirmed and expected (Eberwein 1999). Studies have documented widely held beliefs that men have stronger sex drives than do women, and that men are more easily aroused (Sakaluk et al. 2014; Scully and Bart 1973). Cultural adages like the one arguing that "men think about sex every seven seconds" persist even when debunked by scientific and psychological studies (Alexander and Fisher 2003; Michael et al. 1994) because they are consistent with dominant conceptions of masculine sexual desire. Desire and sexual interest are thought to be such integral parts of masculine sexuality that the absence of sexual desire in men is often pathologized and treated using drugs like Viagra (Marshall 2006). Affirming and demonstrating sexual desire is an important part of identity formation for teenage boys. CJ Pasco (2007) documented the ways that demonstrating heterosexual interest and desire was central to performing masculinity in her study of high school aged young men. This encouraged sexual interest and desire translate into expectations of sexual activity that ultimately increase male social status (Wiederman 2005).

Many studies agree that the sanctions against male sexuality are fewer in comparison with female sexuality (Laws and Schwartz 1977; Sakaluk et al. 2014), and that the rewards for male sexual activity and achievement are central to performing masculinity (Pascoe 2007). Sexual scripts traditionally available to men describe men as initiators of sex, as sexual actors, and as sexual subjects who admire and approach women as the objects of a sexual encounter (Hartley and Drew 2002; Messner 1992; Sakaluk et al. 2014). Adolescent males are encouraged to explore sex casually, recreationally and to increase their overall number of sexual partners as they mature (Kimmel 2007). Male peer groups are often the intended audience of masculine sexual 
accomplishment; as Laws and Schwartz write "the male peer group encourages its members in conquest and applauds their scores" (1977:107). This behavior is in stark contrast to female peer groups who regularly police each other's sexual activity, resulting in a tendency for women to 'round down' their number of sexual partners when asked (Alexander and Fisher 2003).

Previous research has explored the way that masculine norms are expressed in the negotiation of safe sex practices. These studies uncover a link between masculinity and sexual risk taking, especially in the form of condom resistance. Psychologists Donald Tomkins and Silvan Mosher (1988:60) write that an essential component of the sexual script available to men is to view "danger as exciting," and as an opportunity engage in risk-taking to prove one's masculinity. Studies like Noar and Morokoff's (2002:43) find this norm to have empirical consequences; they conclude from their sample of 272 heterosexually active men that "higher endorsement of masculinity ideology was related to more negative condom attitudes."

Beyond condom resistance, some scholars have proposed that a more troubling consequence of the traditional masculine sexual script is the way that it perpetuates sexual violence against women. In their quantitative study, researchers Murnen, Wright and Kaluzny (2002) found adherence to masculine ideology to be correlated with sexual aggressiveness towards women. Other literature also concludes that the sexual scripts traditionally taken up by men that described men as sexually assertive and aggressive, coupled with a belief that women often say no to sex when they mean yes, may foster and legitimize sexual violence (Byers 1996; Murnen, Wright and Kaluzny 2002). 
Several new studies suggest however, that masculine sexual scripts can change and may be changing (Anderson 2008; Seal and Ehrhardt 2003). Researcher Eric Anderson (2007) positions his recent ethnographic study on masculinity in fraternities in contrast to R. W. Connell's conception of hegemonic masculinity (Connell 1983). Anderson finds that some of the men in his study practice what he calls 'inclusive masculinity', a masculine ideology “based on social equality for gay men, respect for women, and racial parity and one in which fraternity men bond over emotional intimacy" (2008:1). Although Anderson's findings are hopeful, they are also recently contested (see de Boise 2014). The above mentioned qualitative study done by David Seal and Anne Erhardt (2003) using 100 interviews with men living in urban New York City also concluded a shift in the traditional masculine sexual script. They found that many of their participants held conflicting opinions of the masculine sexual script, and expressed increased desire for emotional intimacy with their partners (Seal and Ehrhardt 2003).

\section{Traditional Feminine Sexuality}

The traditional sexual scripts available to women are constructed as complementary to the masculine script; in contrast to men, women are described as emotion and relationship-focused, absent of active sexual desire, sexually passive and defensive (Gagnon and Simon 1973; Wiederman 2005). Investment in romantic love is encouraged in adolescent females, while sexual desire and talk of sexual pleasure is discouraged (McCabe et al. 2010). Women are repeatedly described as lacking in sexual desire in contexts ranging from the sex education classroom (Fine 1988) to gynecology text books (Scully and Bart 1973). In adolescence, women become aware of the social 
repercussions for violating these traditionally feminine scripts, and the social consequences associated with sexuality become a major theme in communication about sex for women. Facing the dangers and risks of sexuality, sexual 'gatekeeping' is established as a female role in dating and courtship (Alexander and Fisher 2003; Jackson and Cram 2003; Sakaluk 2014; Wiederman 2005).

Previous research indicates that for women, the social consequences of active sexuality are learned throughout adolescence. The 'sexual double standard' as defined by feminist researchers, is a widespread norm that rewards (hetero)sexual activity for men with an increase in social status, and penalizes female sexual activity with a decrease in social status (Jackson and Cram 2003; Laws and Schwartz 1977; Pascoe 2007; Wiederman 2005). The fact that sexually active men are praised as 'studs', but no comparable accolade exists for sexually active women in mainstream culture, is an example of this pervasive double standard. In their study of sexual script adherence in college-aged men and women, researchers John Sakaluk, Leah Todd, Robin Milhausen, and Nathan Lachowsky (2014) found that this sexual double standard was reproduced by both male and female participants, who equally acknowledged that sexually active women are often labeled as 'sluts'.

This greater risk of a damaged reputation makes sexuality a "risky enterprise" for young women (Jackson and Cram 2003). Because sexual activity is seen as potentially dangerous for women, scripts taken up by women prescribe that sexual activity be limited and be restricted to the context of a committed relationship (Wiederman 2005). In the knowledge that their daughters are sexually vulnerable, parents often warn them to be alert and defensive of sexual advances made by their male peers (Nolin and Petersen 
1992), further scripting young women as sexual gatekeepers. In their 1988 study, sociologists Charlene L. Muehlenhard and Lisa C. Hollabaugh surveyed female undergraduates in exploration of the practice of "token resistance" (saying no but meaning yes) to sex. They found that $39 \%$ of their participants reported engaging in token resistance, and found women's gender role attitudes to be predictive factors. Muehlenhard and Hollabaugh conclude their study by arguing that "given society's sexual double standard, token resistance may be a rational behavior" (1988: 872). Scholars note that the female gatekeeping role is complementary to masculine sexuality; it allows men the freedom to adopt the more aggressive and uninhibited approach to sexuality in malefemale relationships seen as necessary for coercing and outwitting potential partners (Wiederman 2005).

Feminist researchers have theorized the many ways that the sexual scripts traditionally available to women are ultimately disenfranchising. These feminine scripts offers no language with which to affirm sexual desire and experience among women. Sociologist Deborah Tolman (2002) explored the way that the feminine script frames sexuality for adolescent females in her study using interviews with 30 high school-aged girls. She finds evidence of intense internal conflict among her participants as they process their emerging sexual feelings. Tolman writes "the terror some girls feel about the possibility of pregnancy and often truly ruinous consequences, could constitute an incessant source of trauma" (2002:53). She continues that the fear associated with sexuality that teenage girls experience as they learn the sexual scripts available to them can cause them to disassociate "from their authentic thoughts and feelings" (2002:54). Similarly, Michelle Fine's formative work uncovered a 'missing discourse of desire' in 
sex education curriculum that leaves young women without a script to affirm themselves as sexual beings. Fine writes that this missing discourse distances women from the sexual subjectivity that is traditionally afforded to men (1988).

\section{Sources of Sexual Learning}

In order to understand the sexual scripts available to men and women as they learn about sex in adolescence, it is necessary to define their primary sources of sexual learning. Previous literature has named the family, peer groups, the internet, and schoolbased sex education as important locations of formal and informal sex education (Bleakley et al. 2009; Somers and Surmann 2005). While school-based sex education remains the focus of this study, understanding the ways that sexual scripts are presented and communicated in more informal settings is an important comparison, as it allows for a more in depth analysis of the sex education classroom and the perpetuation of gendered sexuality in society overall.

\section{The Family}

Parents are often described as primary agents of socialization for their children, and family norms have tremendous influence on identity and behavior (Hutchinson et al. 2003; Shartshall, Santelli and Hirsh 2007). Previous research has indicated that sex education done within the family has promise for reducing risky sexual behavior among adolescents (Hutchinson and Cooney 1998; Whitaker and Miller 2000). This may be due in part to the fact that children often have established trust and respect with their parents that is sometimes lacking with sex education teachers (Whitaker and Miller 2000). 
Studies on the topic find important gender differences regarding the frequency of conversations about sex in the family, concluding that mother-daughter conversations are the most common and in depth. Sons receive very little communication about sex from either parent (Epstein and Ward 2008; Jaccard, Dittus and Gordon 2000; Nolin and Petersen 1992; Sneed 2008). This disadvantage for sons could be because mothers tend to do most sex educating within the family (Nolin and Petersen 1992, Sneed 2008), and both sons and daughters report more comfort communicating about sex with a same gender parent (Nolin and Petersen 1992).

Amy Schalet's (2011) comparative study documents what she calls a dramatized attitude towards adolescent sexuality present in American culture. This is in contrast to other counties, like the Netherlands who take on a view of teenage sexuality as more normalized, something that is "accepted as a part of adolescent development and relationships" (2011:205). Schalet argues that the dramatization of adolescent sexuality leads American families to understand sex among teenagers as "dangerous and undesirable", and that this results in American parents heavily regulating their children's behavior, especially their daughters (2011:206). Further, knowledge of the societal consequences and risks associated with female sexuality may have influence on parents' motivation for conversations with their daughters about sex (Nolin and Petersen 1992). Nolin and Petersen's (1992) study using data from questionnaires and focus groups with 84 families, found that daughters are much more likely receive parent communication about what they call 'sociosexual issues,' or sexual morality than are sons. In their study parents acknowledge the influence of the sexual double standard on their communication 
strategies; as one parent admitted, "I have consciously or subconsciously assumed that, hey, I don't have any girls; I don't have to worry" (1992:74).

Because daughters hear more about sex and sexual behavior in their families than do sons, this can mean that sons seek sexual information from other sources. Epstein and Ward (2008) found in their mixed-method study that boys name the media and peergroups as more important sources of sexual learning in comparison to their families.

\section{Peer Groups}

Gender differences in peer-group conversations about sex can also mean important distinctions in the quantity and quality of sexual communication men and women experience in adolescence. While they learn very little about sex from their families, men report learning more about sex from peers as teenagers than from any other source (Epstein and Ward 2008). This is in contrast to women, for whom sexual interest is taboo; they report limited and heavily policed conversations among their peer groups (Chambers, Ticknell, and Van Loon 2004).

Previous research has illustrated the ways that sex talk among teenage boys is an important form of homosocial bonding (Flood 2008). The performative aspects of these conversations have also been explored, illuminating the ways that recounting sexual stories and sharing sexual information reinforce heterosexual masculinity among men as they work to establish their identities in adolescence (Epstein and Ward 2007; Flood 2008; Kehily 2001; Pascoe 2007). In her qualitative study exploring the links between heterosexuality and masculinity in adolescents' interactions, sociologist Mary Kehily writes that "within the male peer group, the demonstration of competence and fear of 
ignorance become familiar tropes in the articulation of a masculinity that is sexually knowing and heterosexually active" (2001:179).

In stark contrast, several studies exploring the ways that teenage girls communicate about sex find conversations in female peer groups to be much more limited, and focused mostly on romance and relationships (Chambers, Ticknell, and Van Loon 2004). Researchers Deborah Chambers, Estalla Ticknell and Joost Van Loon (2004) found in their study of teenage peer groups in school that girls speak less explicitly about sexuality and sometimes use words like "slut" in conversation to police female peers who seem overly interested in sex.

\section{The Internet}

Previous research also indicates gender differences regarding what adolescents learn about sex online (Hald 2006; Leiblum 2001; Mesch 2009; Ybarra and Mitchell 2005). Pornography is more easily and anonymously accessed online, and some researchers have hypothesized that pornography is sought out by adolescents as a source of sex education (Allen 2006; Mckee 2007; Tjaden 1988). A report on the subject using data from the Youth Internet Safety Survey found a gender gap in pornography-seeking: "seekers of pornography, both online and offline, are significantly more likely to be male, with only 5\% of self-identified seekers being female" (Ybarra and Mitchell 2005). Pornography is the foremost content accessed by men online (Leiblum 2001) and these high consumption levels lead to important sexual learning differences that may contribute to the sexual scripts differentially available to men and women. 
Being sexually knowledgeable is an important aspect of the dominant masculine script (Wiederman 2005), and pornography can act as a source of this sexual knowledge for the unexperienced. A second motivation for pornography consumption proposed by previous research is an opportunity to perform masculinity in peer groups (Albury 2014). The sexual experience, knowledge, and heterosexual attraction demonstrated through pornography consumption and discussion in male-peer groups are all key aspects of the dominant conceptions of masculine sexuality.

Previous research is mixed about women's pornography consumption habits online, but it is clear they report seeking pornography in much fewer numbers than do men (Ybarra and Mitchell 2005). Barriers proposed could be physical, stemming from the fact women have less literacy and access to technology than men do (Leiblum 2001), but more likely they are social. Researcher Gustavo Mesch theorizes about the dynamic and interactional nature of the internet as a source of knowledge, writing that "navigating the web involves actively choosing to point and click on links that appear on most pages. Certainly, users have different social and psychological needs that motivate their choices" (2009:604). Because the internet is interactional and requires users to actively seek out content, restrictive social norms may limit what teenage girls think is permissible for them to search online. Research indicates that women most frequently use the internet to access email, chat groups and discussion forums (Leiblum 2001), reflecting cultural attitudes about femininity that script women as relational, instead of sexual.

\section{School-based Sex Education}


Although public support for sex education in schools remains high (National Public Radio 2004), what is taught about sex through the use of these programs is controversial (Carpenter 2005; Luker 2007). Formal sex education can be traced from the industrialization of the early 1900s through the implementation of the first sex educational video "Damaged Goods" that served to warn the soldiers of World War II about the dangers of syphilis (Cornblatt 2009; Irvine 2004). Its history includes the founding of the Sexuality Education and Information Council of the United States (SEICUS) in 1964 and the federal funding streams of the 1990s that instituted the prevalence of abstinence-only curricula in public schools (Carpenter 2005; Cornblatt 2009; Luker 2007). Today, while political ventures into sex education lean towards more comprehensive models, 'culture wars' over the content of sex education rage on at the local level (Irvine 2004; Luker 2007). Empirical explorations have noted the ways that sex education content actually varies from school to school, and can depend upon each school's specific socioeconomic context (Fields 2008). Schools that are more rural, and more politically or religiously conservative are more likely to teach sex education that is abstinence-based (Fields 2008, Landry et al. 2003).

Studies analyzing the efficacy of specific curricula abound. Most demonstrate the failures of abstinence focused programs to delay or inhibit the 'risky' sexual behavior of the teens who participate in them (Kirby 2002, Kirby 2008, Walcott, Chenneville and Tarquini 2011). Some indicate that more comprehensive models of sex education, which include instruction on contraception and safe sex practices, achieve higher rates of success in delaying the initiation of sex and increasing contraceptive use (Kirby 2008). Research has also indicated that school-based sex education programs can alienate sexual 
minority youth, especially when these programs are abstinence focused (Fisher 2009). The gay and bisexual young adults interviewed in Fisher's (2009) study reported feeling isolated and angry in response to curricula that was structurally heteronormative.

Sex education that is 'danger focused' has been thought to be problematic, especially when danger messages are directed at female students (Hartley and Drew 2002). Gendered messages that reproduce dominant sexual norms in this way have the potential to reinforce the sexual double standard that legitimizes male desire and suppresses female desire (Hartley and Drew 2002; Tolman 2002). Literature that explores the juncture of sex education and sexual scripts is limited, but offers important insight for this project.

\section{Sexual Scripts and Sex Education}

The sex education classroom is an important location through which to understand the sexual scripts communicated to adolescent men and women as they develop sexual attitudes and identities in our social world. Sex education has been described as a "mechanism for educating, or socializing newcomers into the system" of social sexuality (Laws and Schwartz 1977:6); adolescents are given messages about sex as they are ushered into adult masculinity and adult femininity. Previous research has indicated that schools are important locations of gender and sexual socialization (Pascoe 2007; Thorne 1993). Students learn social lessons both in the classroom and other social environments at school (Pascoe 2007; Thorne 1993; Wentzel and Looney 2007). Analyses of gender socialization in elementary schools point to an early construction of masculine behavior among boys, especially as behavior that is individualistic and 
assertive. Feminine behavior is defined in contrast as reserved, passive and dependent (Thorne 1993). When teaching about sex in schools, it can be hypothesized that gender differentiated sexual scripts will be communicated in some form (Hartley and Drew 2002).

Studies that explore sex education in relation to gender and sexual scripts have used varying methodologies and have yielded various conclusions. Gordon and Ellingson's (2006) research focused on how students interpret 'pleasure and danger messages' in sex education curriculum. Although 'danger messages' are thought to be directed primarily at girls, their study determined that a student's interpretation of these messages depended on which message they identified with personally. This study concluded that personal identity and the experience of the individual is integral in how sex education messages are interpreted.

Several studies explore the sex education experiences of boys. Allen's (2006) research focused on the responses of male students to their sex education program. As the unit of analysis, most of the students' evaluative remarks include explicit and offensive comments. The author concludes that these boys' responses to sex education illustrate their challenge to authority and the assertion of their sexual agency as young men (Allen 2006). Similarly, Haste's (2013) research detailed the experiences of boys in sex education programs, and the "problems that boys face in their efforts to obtain information about sex and to forge sexual identities" in a restrictive classroom setting (Haste 2013:515).

Lastly, a more relevant study done by Hartley and Drew (2002) undertook a content analysis of contemporary sex education films. They analyzed these films for the 
presence or absence of gender differentiated scripts. Their conclusions determined that a majority of films contained gender differentiated scripts, and placed emphasis on the 'dangers' associated with female sexuality (Hartley and Drew 2002).

\section{Conclusion}

This review detailed previous research exploring gendered sexuality, the sexual scripting approach, and the primary sources of sexual learning, which include the family, peer groups, media, and the internet, with a special focus on school-based sex education. Much research has been done regarding school-based sex education; these studies have explored the influence that the social and regional context of sex education program has on its content (Fields 2008), the ways that students interpret sex education lessons (Gordon and Ellingson 2006), and the efficacy of different sex education programs in decreasing 'risky' sexual behavior (Kirby 2002, 2008). However, with the exception of one study (Hartley and Drew 2002), there is little research on how men's and women's experiences with school-based sex education influence the different sexual scripts they have access to and take up.

The objective for this project is to examine the experiences of men and women with formal sex education programs, especially in regard to the specific sexual scripts made available to them during sex education. While acknowledging that interaction with sexual scripts occurs in a multitude of settings over the life course, school-based sex education is the focus of this analysis because of the explicit messages communicated to adolescents during a very formative stage. The following research questions guide this analysis: 
1) How do men and women describe the sexual scripts that were communicated to them during formal and informal sex education?

2) How do the sexual scripts communicated in formal (school-based) and informal (i.e. family, peers, and the internet) sex education compare?

3) How does access to these sexual scripts vary by gender? 


\section{CHAPTER 3: METHODS}

This research is an interview-based study that seeks to examine the experiences of men and women with formal and informal sex education, especially in regard to the specific sexual scripts made available to them during school-based sex education programs. This methodological strategy aims to understand what sexual scripts are communicated during sex education, and how access to these scripts varies by gender. Research was undertaken through the use of semi-structured, in-depth interviews with 20 participants, including equal numbers of men and women, which allowed specific questions regarding the experiences of men and women with school-based sex education programs, sources of sex education outside of school and how their perspectives on sex have changed over time to be addressed. The criteria for subject recruitment was that potential participants (1) be between the ages of 18 and 31 and (2) currently live in the Portland, Oregon metro area.

\section{Data Collection}

Data collection was conducted using semi-structured interviews. The participants in this study were men and women living in the Portland metro area between the ages of 18 and 31 . This age range was an important requirement because relatively younger participants were more likely to have stronger memories of their sex education experiences. Although participants may have been somewhat removed from their sex education programs, accuracy was not the goal of this research. Rather, semi-structured interviews were used to gain information about participants' understandings of their experiences. Social psychologist Terri Orrbuch (1997) defends this nature of accounts by 
saying "The accounts-as-stories framework is better able than standardized survey instruments to represent the rich, complex, interwoven reports that investigators are currently collecting" (Orrbuch 1997:461). Recruiting participants over the age of 18 was important and necessary to bypass the complicated process of obtaining parental consent. This strategy has been used in previous research regarding sex education (Fisher 2009; Gordon and Ellingson 2006). Additionally, interviewing adults was essential for understanding how interactions with sexual scripts inform the present sexual experiences of participants in young adulthood. This approach also allowed research questions about how sexual scripts are taken up, retained and reformulated over time to be addressed.

Participants were recruited through flyers and classroom presentations at Portland State University. A university campus was chosen as the location for recruitment because of its high concentration of individuals in the target age range. Although it is a possibility that young adults who do not attend college may have had different understandings of sex education, recruiting from a state university like Portland State University was important because of its concentration of individuals in the desired aged group. Several waves of recruitment were undertaken during the spring, summer and fall of 2014. Professors of large introductory classes were contacted with a request to give a short description of the research and pass around a sign-up sheet in their classes. Recruitment was conducted in Psychology, Sociology, History, Economics, Child and Family Studies, American Sign Language, Mathematics, French, Black Studies, Queer Studies, and University Honors classes, so as to increase diversity of experience in the sample. Overall, classroom recruitment talks were given in over 20 classes, and several professors also posted information about the study on their course's online page. During initial recruitment, 
students were encouraged to participate without stating demographic restrictions with care not to stigmatize interested participants. A small survey was then issued to interested participants to obtain basic background information and to identify participants who meet the age requirements of this study. This initial survey also allowed a selection of equal numbers of male and female participants, and an aim for diversity in participants with private and public school experiences. ${ }^{1}$ Roughly 130 students signed up in class to receive more information about the study and 32 students responded via email to the initial survey indicating an interest in being interviewed. Eleven respondents were then either excluded due to age restrictions or did not respond to subsequent emails about setting up in-person interviews, and one incoherent interview was discarded resulting in the remaining 20 interviews. $^{2}$ In initial recruitment, male participants proved harder to recruit than female participants, and men signed up in class in much fewer numbers than did women. To increase the number of male participants, only men were recruited from classes in the final wave of recruitment. Snowball sampling was also used to reach male participants during this last wave. At the conclusion of recruitment, 18 participants were recruited through classroom talks, one was reached through a posting on a course website and one male participant was reached through snowball sampling.

\footnotetext{
${ }^{1}$ Because the literature suggests that sexual minority students have unique experiences with sex educationexperiences that warrant significant future research, the initial intention was to exclude them from this study (Fisher 2009). However, it proved more difficult than expected to recruit 20 participants who identify as heterosexual, possibly due in part to Portland's sizable LGBTQ community, recently ranked $4^{\text {th }}$ largest in the nation at $8.1 \%$ of Portland's population (Gates 2006). After initial interviews with participants who identify as pansexual, queer, bisexual and gay it was concluded that these narratives did not detract from the overall focus of the study, but contributed valuable data regarding sexual scripts and sex education. ${ }^{2}$ One additional interview was excluded from analysis due to complications with a participant that included issues with comprehension and communication during the face-to-face interview.
} 
Participant demographic information can be seen in Table 1 below. Nine participants identified as female, one identified as both female and gender fluid, and ten identify as male. Participants ranged in age from 18-31. Fourteen participants exclusively attended public schools, where they participated in sex education programs. Three participants did at least part of their schooling at private catholic schools, and one participant attended a private Jewish school. Two participants attended schools that were private but not religiously affiliated. Participants also varied in the ways they described their sexual identities. Twelve participants identified as heterosexual, two as bisexual, four identified as pansexual, one identified as gay and one participant identified as both pansexual and queer. All participants were students pursuing bachelor's degrees at the time of the interview.

Participants were interviewed in empty classroom space on PSU's campus. Interviews lasted from 30 to 90 minutes and were semi-structured and conversational. An initial interview guide was developed under the influence of previous interview based studies of sexuality (i.e. Carpenter 2005 and Tolman 2002) to guide the conversation. The guide was revised as data collection and analysis proceeded, with the addition of useful probes and the rewording of questions for clarity. Although interviews had a conversational flow, extra effort was made to cover all relevant concepts. During the interview participants were asked about their school-based sex education experience, especially in regards to learning about anatomy and biology, sexual responsibility, virginity and abstinence. They were also asked about learning about sex from sources outside of school, like from family, friends and the media in comparison with formal sex 
education programs. Lastly, participants were asked about their perspectives on sex, and how their perspective might have changed since learning about sex in school.

Previous research has noted the informal dynamics inherent in the school setting (Fields 2008, Thorne 1993), however, in this study, school-based sex education is referred to as 'formal' because of its structure and clear objectives. This structure is distinct from other sources of sex education, like peer groups, families and the internet which are referred to as 'informal'. As is acknowledged in the work of Gagnon and Simon, sexual scripts exist on different levels and are internalized and interpreted differently by the subject (Gagnon and Simon 1973). Bearing this concept in mind, it was clear that sex educational experiences would be interpreted through the identities and experiences of participants. Questions regarding sources of sex education outside of school and sexual experience and perspective were hoped to give a more complete context to individuals' understandings of their sex education experience.

Interviews were audio recorded and uploaded to a password protected file and transcribed by the researcher. After transcription, all identifying information, like the names of participants and their families or partners, and the names of schools and home towns was removed or changed to maintain confidentiality. Transcriptions of interviews were uploaded into Dedoose software and coded. 
TABLE 1: STUDY PARTICIPANT DATA

\begin{tabular}{|l|l|l|l|l|}
\hline Name & \multicolumn{1}{|l}{ Age } & Gender & School Types & Sexual Identity \\
\hline Taylor & 23 & Female & $\begin{array}{l}\text { Private Catholic Elementary, Middle, and High } \\
\text { School }\end{array}$ & Heterosexual \\
\hline Tori & 18 & Female & Public Elementary, Middle, and High School & Bisexual \\
\hline Audrey & 25 & Female & Public Elementary, Middle, and High School & Pansexual \\
\hline Kelsey & 27 & Female & Public Elementary, Middle, and High School & Heterosexual \\
\hline Lisette & 25 & Female & Public Elementary, Middle, and High School & Pansexual \\
\hline Stephanie & 21 & Female & Public Elementary, Middle, and High School & Heterosexual \\
\hline Courtney & 22 & Female & Public Elementary, Middle, and High School & Pansexual/queer \\
\hline Molly & 19 & Female & Public Elementary, Middle, and High School & Heterosexual \\
\hline Julia & 23 & Female & $\begin{array}{l}\text { Private Catholic Elementary and Middle School, } \\
\text { Home High School }\end{array}$ & Heterosexual \\
\hline Crystal & 28 & $\begin{array}{l}\text { Female, } \\
\text { Fluid }\end{array}$ & Public Elementary, Middle, and High School & Pansexual \\
\hline John & 22 & Male & Public Elementary, Middle, and High School & Heterosexual \\
\hline Wayne & 31 & Male & Public Elementary, Middle, and High School & Heterosexual \\
\hline Jake & 21 & Male & Public Elementary, Middle, and High School & Bisexual \\
\hline Jonah & 22 & Male & $\begin{array}{l}\text { Public Elementary and High School, Private } \\
\text { Academic Middle School }\end{array}$ & Heterosexual \\
\hline Caleb & 26 & Male & $\begin{array}{l}\text { Public Elementary and Middle School, Private } \\
\text { Catholic High School }\end{array}$ & Heterosexual \\
\hline Ben & 22 & Male & $\begin{array}{l}\text { Private Jewish Elementary and Middle School, } \\
\text { Public High School }\end{array}$ & Heterosexual \\
\hline Howard & 25 & Male & Public Elementary, Middle and High School & Pansexual \\
\hline Cameron & 30 & Male & $\begin{array}{l}\text { Private Academic Elementary School, Public } \\
\text { Middle and High School }\end{array}$ & Heterosexual \\
\hline Kevin & 19 & Male & Public Elementary, Middle and High School & Gay \\
\hline Julius & 18 & Male & Public Elementary, Middle and High School & Heterosexual \\
\hline
\end{tabular}


Data Analysis

Interview data was managed and analyzed primarily using Dedoose software and Excel. Because few studies have been conducted using semi-structured interviewing on this subject, the style of data analysis relied less on pre-constructed coding schemes and more on internal interpretation. Some codes were developed from the data, while additional external examples were used to guide the development of these codes. In Hartley and Drew's (2002) relevant study, the researchers developed a coding system to indicate scripts in sex education films that were 'gender differentiated' or 'gender symmetrical'. Their coding process proved helpful in guiding analysis in this project.

Using an inductive approach, initial coding was done by examining interview data, and exploring all potential concepts that could be detected and their interrelationships (Charmaz 2006). The first phase, open coding led to the development and naming of broad code categories. During the next analytical phase, focused coding, the most common codes were determined and analyzed. During axial coding relationships between codes were noted and code families were constructed. Lastly, theoretical coding was undertaken to take note of common themes and narratives were illustrated by code categories.

During this last phase, six scripts were developed to describe common themes in participant accounts regarding communication about sex. As was detailed in the literature review, sexual scripts can be thought of as 'blueprints' for appropriate sexual behavior and interaction, and thus themes that emerged from the data that described appropriate 
sexual behavior and meaning for an individual were labeled as scripts (Wiederman 2005). Borrowing from Charmaz's (2006) approach, a series of memos were taken during the coding process and these memos were integral in the development of these resulting six sexual scripts. For example, a broad code category 'danger' that was used to mark narratives about the dangers and consequences of sexuality lead to the development the Danger Script, the Social Consequences Script and the Gatekeeping Script. The 'open' code category, indicating open and affirming communication about sexuality, was differentiated based on messages about desire and messages about active sexuality which were developed into the Agency Script and Desire Script respectively. The 'open' code category was further refined to also indicate communication about active sexuality and sexual risk taking, resulting in the Risk-Taking Script. Care was taken to make sure codes and resulting scripts were not too broad or too narrow. Using categories like Hartley and Drew's (2002) helped guide the initial analysis, but these categories were added to and refined as coding progressed. It is important to note that while some participants spoke explicitly about their sex education experiences as heteronormative, the assumption of heterosexuality is both explicit and implicit in all the sexual script categories developed in analysis. While many participants in this study do not identify as heterosexual, the narratives of these participants are not in contrast with heterosexual-identified participants, and all participant accounts exhibited gendered differences in sexual learning and access to sexual scripts. 
TABLE 2: SEXUAL SCRIPT CATEGORIES

\begin{tabular}{|c|c|}
\hline Sexual Script & \\
\hline Danger & $\begin{array}{l}\text { Sexuality is dangerous. Emphasized outcomes of sex are its physical } \\
\text { dangers like STD acquisition and pregnancy. }\end{array}$ \\
\hline Desire & $\begin{array}{l}\text { Sexual desire is normal and to be expected. Sexual feelings are a part of } \\
\text { individual identity and demonstrating interest in sex is okay. }\end{array}$ \\
\hline Agency & $\begin{array}{l}\text { The individual is in the sexual driver's seat and is capable of own sexual } \\
\text { decision making. They are a sexual actor, and sexual activity is expected } \\
\text { and affirmed }\end{array}$ \\
\hline Risk-taking & $\begin{array}{l}\text { The individual can and should dismiss warnings about the dangers of } \\
\text { sexuality. The more boundaries are pushed in sexual experience, the more } \\
\text { rewards. }\end{array}$ \\
\hline Social Consequences & $\begin{array}{l}\text { Sexuality has social consequences, most often a damaged reputation. } \\
\text { Interest in sex or being sexually active results in social repercussions, } \\
\text { possibly name calling or being considered unfit for future partners. }\end{array}$ \\
\hline Gatekeeping & $\begin{array}{l}\text { The individual's role is the sexual gatekeeper. Peers will make sexual } \\
\text { advances, and the individual's job is to be alert and defensive. The } \\
\text { individual is responsible for controlling, regulating and setting boundaries } \\
\text { sexual relationships. }\end{array}$ \\
\hline
\end{tabular}




\section{Significance for Knowledge}

In contrast with the body of extensive quantitative research on the efficacy of sex education programs (Kirby 2002; Kirby 2008; Walcott et al. 2011), this study intends to provide a qualitative understanding of the sexual scripts communicated to men and women during sex education in school and, comparatively, from other sources outside of school. Little research has been done on how men and women experience formal sex education differently in school, and this study explores and situates the school setting by examining the messages men and women get from parallel sources of sexual education like family, friends and the media. An exploration into the subjective experiences associated with sex education contributes important and overlooked understandings about overt and covert sexual scripts, and their relationship with formal school programs.

Previous studies have explored the development of sexual scripts (Carpenter 1998; Tolman 2002) the presence of these scripts in different social contexts (Bowleg et al. 2004; Maticka-Tyndale et al. 2005; Seal and Ehrhardt 2003) and the implications of sexual scripting in society (Krahe et al. 2007; Tolman 2002). However, little research has been done regarding formal sex education programs in school, which are a key juncture of sexual socialization and sexual development (see Hartley and Drew 2002 for an exception). This study also brings new insight by exploring school-based sex education with an added comparison to more informal sex education experiences of participants. This research will add to sociological literature by using a scripting approach to understand men's and women's different experiences with sex education. Significance for Practice. 
This study hopes to inform the debate surrounding sex education by providing insight into the ways that men and women experience sex education differently and internalize different messages about sex both in school and from sources outside of school. Gendered messages imparted through sex education could mean a reproduction of dominant sexual scripts that can result in a pervasive sexual double standard (Hartley and Drew 2002; Tolman 2002). A better understanding of sexual scripts in relation to sex education could improve curriculum and practices, meaning higher quality sex education for all students.

\section{Limitations}

This research includes some limitations to be acknowledged and considered. This study does not claim to be generalizable and relies on a small sample size. It is only be able to describe the understandings of a small group of students in the Portland metro area. In addition, although Portland State University claims to have an exceptionally diverse student body, sampling from university students could limit variation in the experience and background of participants. While not generalizable, this case study is useful in a broad sense; it offers insight into assessing the sexual scripts communicated during formal and informal sex education generally.

Also, as a female researcher interested in sexuality it is important to acknowledge that there is a possibility that participants may feel nervousness or discomfort, especially male participants. Previous researchers have theorized about the unique circumstances and barriers associated with gender differences in interviewing, especially those present when women interview men (Arendell 1997; Gailey and Prohaska 2011; Pini 2005; 
Schwalbe and Wolkomir 2001). Gender is understood in this research as something that is constructed, achieved and performed in daily life and the interview setting is no exception. Schwalbe and Wolkomir (2001: 91) write that "an interview is both an opportunity for signifying masculinity and a peculiar type of encounter in which masculinity is threatened". These authors go on to note that differences in gender, as well as the content of the interview can heighten the "threat potential of an interview" (2001:91). Allowing participants some control over when the interview would take place, briefing them on the direction of the interview guide before its start and allowing participants to ask questions at its conclusion were all attempts to shift away from the power dynamics implicit in the researcher-researched relationship, and to lessen the effect of gender difference on the quality of the data. Overall, male participants in this study were generally descriptive and open about potentially sensitive topics like pornography, family life and their sexual histories indicating that they felt some sense trust and comfort during the interview. At the end of each interview, participants were offered an opportunity to read a preliminary draft of the study before its conclusion in order keep the research process as collaborative as possible. Every attempt was made to decrease discomfort and to establish trust and rapport with interviewees, to ensure the quality of interview data. 


\section{CHAPTER 4: SEXUAL SCRIPTS AND FORMAL SEX EDUCATION}

When prompted, participants recall facts that they learned in sex education about topics like bodies, STDs, and safe sex practices. However, in addition to factual information, their narratives also reveal messages and attitudes about sex and sexual behavior, or sexual scripts communicated during sex education that are explored in this chapter. Drawn from participants' accounts, the sexual scripts remembered generally by both men and women during sex education are made up of danger-based messages that warn teens of the physical dangers of sex, and script sexuality as strictly heterosexual. Participants' accounts show that the sexual scripts remembered by male participants during sex education affirm their emerging sexual feelings and describe them as sexual actors. In comparison, the sexual scripts remembered by female participants warn them of the social consequences of their sexuality, describe them as sexual gatekeepers, and define sexuality as a taboo topic, not to be discussed. Through the narratives of the men and women interviewed for this study, the scripts available to teenagers in general, and the scripts available to teenage boys and teenage girls communicated through sex education are explored.

\section{Experiences with Sex Education}

Participants' narratives in this study offer interesting information about the form and content of school-based sex education. Most participants remember several experiences with sex education: the first in fourth or fifth grade that was meant to inform students about the body changes associated with puberty and physical differences between boys and girls. Audrey, a female participant in her mid-twenties, remembers this 
time: "It wasn't much actually talking about sex and that kind of thing it was just like 'so these are your ovaries'...I remember definitely having to label like the alien looking, internal female ovaries, organs and penis. Like 'here's a side cut that would never occur in nature but label it'." Participants recall that their regular teachers and sports coaches taught students about puberty and menstruation; sometimes videos were shown and most often pictures and diagrams were used to illustrate human anatomy and the reproductive system.

Most participants describe a second sex education class happening in either middle or high school. These programs varied; some participants remember a few weeks set aside during a health class, while others remember a special day where outside instructors, like Planned Parenthood representatives or teen moms, came and presented material. Sex education in middle and high school, as described by participants was more explicitly about sex and sexuality, including topics like pregnancy, contraception, relationships and appropriate sexual behavior. Nine of twenty participants felt that their school-based sex education programs were "abstinence-only," meaning that the central purpose of instruction was to promote abstinence until marriage and to minimize any discussion about contraception and safe sex practices. Four participants remembered the Students Today Aren't Ready for Sex (STARS) program by name, an abstinence-only sex education curriculum implemented widely in Oregon in the early 2000's (SEICUS 2007).

Four participants in this study attended private, religious schools and received sex education in a particular religious context. These participants remember lessons about sexuality infused with moral messages that generally instructed students to save sexual 
activity until marriage, prize their virginities, and avoid peer pressures. Julia remembers "they would talk about how virginity was the most important thing until marriage, that you should just give it to your spouse and nobody else sort of thing. Virginity is everything. Purity, you know.” Three participants attended private secular schools for some part of their schooling. Only one participant, Jake, a man in his early twenties, remembers receiving sex education in this context, and he describes his sex education experiences as "progressive," "open," and recalls an emphasis on connecting students to contraceptives. 
TABLE 3: SEXUAL SCRIPTS IN SEX EDUCATION

\begin{tabular}{|c|c|c|}
\hline Script & Men & Women \\
\hline Danger & $\begin{array}{l}\text { Wayne, Cameron, } \\
\text { Howard, Julius, Jonah, } \\
\text { Caleb, John }\end{array}$ & $\begin{array}{l}\text { Stephanie, Julia, Kelsey, Tori, } \\
\text { Taylor, Molly, Audrey, } \\
\text { Courtney, Crystal }\end{array}$ \\
\hline Desire & $\begin{array}{l}\text { Julius, Jonah, Jake, Ben, } \\
\text { Wayne }\end{array}$ & Courtney \\
\hline Agency & $\begin{array}{l}\text { Wayne, Jonah, Kevin, } \\
\text { Jake, Caleb, Ben, Julius, } \\
\text { Jake }\end{array}$ & Molly, Tori \\
\hline \multicolumn{3}{|l|}{ Risk-taking } \\
\hline Social Consequences & Julius & $\begin{array}{l}\text { Julia, Courtney, Crystal, } \\
\text { Molly, Kelsey, Lisette }\end{array}$ \\
\hline Gatekeeping & & Kelsey, Courtney \\
\hline
\end{tabular}




\section{Sexual Scripts in Sex Education}

Drawn from participants' accounts, the sexual scripts remembered during schoolbased sex education include the danger script consisting of danger-based messages that warn teens of the physical dangers of sex, the desire script affirming the subjects' emerging sexual feelings, and the agency script scripting individuals as sexual actors, capable of their own sexual decision making. The social consequences script describes sexuality as having social repercussions like a damaged reputation and the gatekeeping script scripts the individuals' role as sexual gatekeeper. Through the narratives of individuals interviewed for this study, these scripts and their availability to male and female participants in the sex education classroom are explored. Sex education teachers can be considered agents of sexual socialization for teens, and they articulate scripts regarding appropriate sexual behaviors and feelings through sex education curriculum. Sociologists Beth E. Schneider and Valerie Jenness argue that teenagers "are not in charge of their education and are politically disenfranchised; they have... virtually no cultural permission to construct their own sexuality in their own terms" (1995:91). As teenagers, most participants in this study remember learning during sex education that interest in sex or sexual activity was inappropriate and dangerous, an attitude reflexive of cultural attitudes toward teenage sexuality.

Traditionally, teenage sexuality has been seen as a social problem, hinging on the hormonal drives of adolescents (Bay-Cheng 2003; Fallon 2013). School-based sex education is used as an intervention measure meant to curb uninhibited sexual desire and regulate risky teenage sexual activity (Carpenter 2005; Fine 1988). In response to the 
'moral panic' surrounding teenage sexuality, the scripts available to teenagers in schoolbased sex education cast them as too young to be sexual and as sexually irresponsible. Wayne, a male participant in his early thirties recalls the central message of his sex education program: "It was just that sex is for adults. That once you're old enough you know, it's necessary for the procreation of the species etc. Having babies is great but you should wait until you're financially and emotionally and everything ready for it." In Wayne's narrative, messages from his sex education program warn him that he is too young, and ill-equipped to deal with the outcomes of sexual activity as a teenager.

\section{Danger Script}

Many of the messages about teenage sexuality recounted by participants emphasize this point that teens are too young and ill prepared for sexuality and its associated physical risks. Remembered by 16 out of 20 participants, these messages are not necessarily gender differentiated; Table 2 indicates that seven men and nine women in this study recall hearing messages about the physical dangers of sex as teenagers in their school-based sex education programs. Audrey has a typical narrative:

We had to watch this scary video--I think in seventh grade, of "this is what genital warts look like." I'm like "okay! I don't want that." It was like horribly advanced genital warts, if you really didn't take care of yourself or get anything treated. So, it definitely was defined as a scare tactic I think.

Audrey identifies these sex education strategies used to curb risky sexual behavior in her narrative as "scare tactics". These danger messages recalled by participants include information about the negative physical consequences of teenage sex, most often STD transmission and pregnancy. Societal concerns about adolescent sexuality, channeled into 
sex education curriculum often appeared to students as thinly veiled 'scare tactics'. Molly, a female participant remembers: "The emphasis was like 'look at these STDs. You can get this if you decide to have sex.' And then everybody went around freaking out 'who has an STD?'--kind of thing. It was definitely more fear tactics." Molly remembers the effect that the danger script had on her and her classmates in her narrative by describing the resulting "freak-out".

It may not be surprising that these messages about sexual dangers were being communicated to teens in the sex education classroom. Most participants in this study attended middle and high school when federal funding streams dictated abstinence-only curricula for sex education in schools. To receive federal funds, school-based programs had to adhere to an eight-point definition of abstinence-only content, including the stipulation that the program "teaches that sexual activity outside of the context of marriage is likely to have harmful psychological and physical effects" (SIECUS 2010). Participants' narratives relay some of these harmful effects taught as consequences of teen sex outside of monogamy and marriage. In the case of school-based sex education, the sexual scripts communicated to teens are shaped the by the social and political climate, as cultural scripts often are (Fallon 2012; Gagnon and Simon 1973; Hartley and Drew 2002; Laws and Schwartz 1977). Danger based messages about sex serve to regulate teenage sexuality, in response to the moral panic surrounding teenage childbearing and risky sexual activity. These scripts describing the dangers of teen sex, and the use of abstinence to avoid these risks, were remembered generally by the majority of the participants interviewed, both men and women. 


\section{Desire Script}

The desire script communicates to those who take it up that is normal and to be expected. This sexual script affirms for the individual that sexual feelings are a part of their identity and that demonstrating interest in sex is okay. In line with traditional masculine sexuality, sexual feelings for men are affirmed and defined as natural, especially in comparison to women's sexual feelings (Fine 1988; Tolman 2002). As Sociologist Ken Plummer writes "natural sex serves as a routine resource in accomplishing and reinforcing young men's emerging manliness" (2005:184). Although discussion about sexual desire in school-based sex education was limited in general, in this study more male participants recount having access to this script during sex education can do female participants. Hearing and having access to desire scripts that normalize and affirm adolescent sexual feelings were described by five of the 10 men interviewed for this study in comparison with two women.

When asked if he learned anything about sexual desire during sex education in school, Ben, a male participant remembers hearing: "I think in the terms of like 'you may be having feelings, these feelings are totally healthy.' Definitely that was talked about." Ben remembers feeling affirmed that his early sexual feelings were normal and healthy. Ben goes on to say “I didn’t feel like what I was feeling was wrong. Like I felt like my emotions were my emotions, if that makes sense." Through sex education, Ben had access to a sexual script that affirmed his adolescent, masculine sexuality as "totally healthy". As described by Gagnon and Simon (1973), adolescence for boys means an about-face in sexual socialization. While childhood is scripted culturally as markedly 
nonsexual, for boys being socialized into adult masculinity, adolescence means embracing sexuality and sexual activity. The experiences of these male participants run counter to the findings of Michelle Fine's study (1988), in which she sheds light on a "missing discourse of desire" in school-based sex education which, she writes, is founded on "anti-sex rhetoric" (pg. 29). However, Fine argues that female students are the most impacted and disadvantaged by this "missing discourse", a conclusion that informs the findings of this study, in which fewer women than men recall the desire script during their experiences with sex education in school. In another example of the desire script remembered by these male participants, Julius, responds when asked if he remembers talking about sexual desire in school by saying: "Probably in the sense that it's normal. And that it's not something you should be scared of." This sexual script communicated to these men as teenagers is a part of their transition into male adulthood, as a step in the process of gendered sexual socialization experienced during sex education.

\section{Agency Script}

The agency script affirms for the individual that they are in the sexual driver's seat. The agency script communicates to that actor that they are responsible for and capable of your own sexual decision making. For those who take up the agency script, sexual activity is expected and affirmed. Eight men recall this script describing them as sexual actors in school-based sex education. This is in comparison with only two women, in line with traditional conceptions of feminine sexuality as more passive (Laws and Schwartz 1977). Culturally, sexual activity is expected and often rewarded for men (Wiederman 2005). As adolescents, male participants in this study remember hearing 
scripts that described them as sexual actors, and heard messages about their expected future sexual activity during sex education in school. Jake: "It was like 'well, if you want a hundred percent chance of not getting pregnant or having STDs you could not do it but it's likely that at some point in your lifetime you're going to do it. Let's get you prepared for that'--that was the kind of mentality." In his narrative, Jake remembers hearing that sexual activity for him is normal and expected. At some point, he will be sexual and has the power to make decisions about his sexual behavior. Ben remembers this agency script being communicated to him as well. He recalls of his teacher: "He was like 'guys'--it wasn't in looking down at us, the feeling I got was more 'you are going to do what you are going to do, but these are the best ways to not get pregnant or be safe about it."' In illustration of the agency script, Ben doesn't feel belittled or talked down to, he remembers be treated as sexual responsible and capable.

Learning to view themselves as sexual actors and as sexually active is part of socialization into traditional masculine sexuality for these teenage boys who recount having to the agency script during school based sex education. Even in early adolescence, the more men than women in this study remember hearing that their sexual activity is normal, to be expected and at best, should be minimally mediated with protective measures like contraception. Differential access to desire and agency scripts in the sex education classroom is one explanation for the different set of sexual roles socially available to men and women in adulthood.

\section{Social Consequences Script}


The social consequences script communicates to those that have access to it that sexuality has social consequences. These social consequences of sexual activity are most often result in a decrease in social status and a damaged reputation. For those who take up this script, interest in sex or sexually activity result in repercussions described by participants in this study as possibly name calling or being considered unfit for future partners. More female participants than male participants in this study recount having access to this script in the sex education classroom; as Table 2 illustrates, it is remembered by 6 women and only 1 man. The sexual scripts teenage girls have access to are are largely in contrast to the scripts available to teenage boys, in the same way that adult masculinity and adult femininity operate as complementary.

Adolescence for girls represents a transition from non-sexual childhood into adult femininity where sexual desire is meant to be suppressed or channeled into a committed relationship (Gagnon and Simon 1973). As was detailed in the literature review section, feminist researchers have theorized the ways that these scripts perpetuate a sexual double standard that is ultimately disenfranchising for women, for whom sexuality is scripted as dangerous and entangled with negative outcomes. (Laws and Schwartz 1977; Tolman 2002). Previous work has concluded that sex education often frames female sexuality negatively, emphasizing its consequences and dangers (Hartley and Drew 2002; Fine 1988). The narratives of the female participants in this study demonstrate this sexual script communicated during sex education.

In addition to the danger script that warned both men and women of physical dangers of sex, 6 out of the 10 women interviewed remember hearing messages about the social consequences of their sexuality: that being sexual could damage their reputation, 
affect their social status, and limit their prospects for a future mate. Crystal, a female participant in her late twenties remembers these types of social danger messages:

It's pretty much either you choose to be abstinent or you're going to die, you know? "Your life is going to be ruined" or, there was even a little bit of that sort of scarlet letter "you will be socially ruined" message woven in there... You know, they were like "Well people are going to find out and it's going to ruin your reputation" and "is it worth it? It's just not worth it. So just don't do it."

In illustration of the social consequences script she had access to, Crystal recounts worrying about a ruined reputation as a consequence of being sexually active. In participants' accounts of this script, warnings about teen pregnancy were based on repercussions like damaged reputations and disappointed families, and messages about STDs became social in nature, as Lisette, a female participant remembers:

I remember watching a video about AIDS and this woman who had AIDS--she had a boyfriend and then he was very ashamed that he had sex with her, and they used protection but he was super--like didn't want to date her. And it was very "if you get AIDS no one will want to date you."

Like Lisette, other women in this study remember being warned to limit sexual activity in order to remain available to future male partners and successfully achieve feminine sexuality. Psychologist Michael Wiederman writes of the feminine sexual script that "to be too sexually interested or aggressive, especially outside the context of an intimate relationship, implies masculinity, or desperation, or some other flaw (even if only a 'weak' character or a lack of proper upbringing or restraint)" (2005:488). Kelsey, a female participant in her late twenties remembers the social consequences script during sex education, warning her of the risk of becoming unfit for future partners (Wiederman 2005). She recalls a sex education teacher: "her favorite saying was 'They're not going to buy the cow if they can get the milk for free.' So that was actually commonly held among 
the teachers where they would say just random stuff like that." Kelsey's narrative illustrates a negative message inherent in the social consequences script made available to teenage girls during school-based sex education.

\section{Gatekeeping Script}

Those who have access to the gatekeeping script learn that their role is the sexual gatekeeper. The gatekeeping script warns the individual that others will make sexual advances towards them and that their job is to be alert and defensive. Individuals who take up this script learn they are responsible for controlling, regulating and setting boundaries in sexual relationships. While more men in this study had access to sexual scripts that define them as sexual actors, defensiveness and sexual gatekeeping is central to conception of traditional feminine sexuality in adulthood (Laws and Schwartz 1977; Wiederman 2005). Table 2 indicates differential access to the gatekeeping script as two female participants recount it in their sex education programs in comparison with no men. This gatekeeping script is constructed as adolescents learn about the risks associated with their sexuality. In light of the learned dangers of sexuality, these female participants were subsequently taught through sex education to remain alert and defensive to sexual advances made by their male peers, a characteristic that foreshadows adult feminine sexuality. Kelsey recalls what she felt was the central message of her sex education program: "I would say be always on alert. Because you are always on alert for somebody trying to push you into sex, and then you're always on alert when you're having sex-about STDs and pregnancy, you're always on alert about how other people are going to view you." The gatekeeping script, as illustrated by Kelsey, encouraged her to be alert 
and defensive towards sexual advances and emphasized the dangers of letting her guard down.

Missing an Affirming Script

As Laws and Schwartz (1977) conclude, sexual scripts have many conceptual parallels to language. Dominant scripts provide language that validates the feelings and experiences deemed appropriate and normal for some and leave those with alternative or deviant experiences without scripts and language that affirm them. While some men in this study remember scripts that affirmed their developing sexual desires and feelings in sex education, the most women in this study had access to no such script. Like many female participants in this study, when asked if there was a conversation about sexual desire during sex education in school, Kelsey, remembers: "No, we never had that. I didn't have that conversation 'til college." In this way, most female participants in this study were left without language to affirm their sexual feelings. Teenage girls learn that discussing, processing and affirming their sexuality in adolescence is taboo and many female participants remember experiencing this taboo during school-based sex education sex education. Audrey, a female participant remembers:

Back then it was just something that you weren't supposed to talk about, I guess. In general it's kind of--that's private and you don't share it with everybody and yeah, I guess that's probably what I took away from that. We weren't comfortable asking questions back then.

Audrey remembers learning that sexuality is private, and her experience with this cultural taboo in sex education meant that her and her female peers were not comfortable asking for and sharing information about their sexualities. Demonstrating interest in sexual 
knowledge is in violation of traditional conceptions of feminine sexual, and female participants in this study remember their experiences with this norm as discomfort, silence and hesitancy to ask questions. (Laws and Schwartz 1977) In a similar tone, Crystal remembers: "I think amongst the girls there was just a lot of uncomfortable silence which is very telling to me." She goes on to describe her feelings during her sex education program,

If I had had a question I definitely wouldn't have asked it. You know, if I had been confused about something or curious about something, I'm sure I would have just sat there in shamed silence and not even tried to engage. So I am sure there was a little bit of that sort of embarrassment.

Crystal remembers her understanding that sex was an embarrassing topic, to be responded to with "shamed silence". While some men in this study remember also feeling awkward and embarrassed in the sex education classroom, many of them remember reacting to curriculum with humor instead of silence. Wayne remembers "I think there was a sort of pressure peer-wise in the class not to take it very seriously." Like Wayne, eight out of the ten male participants remember joking or making jokes with their male peers during sex education, often in response to awkwardness. While most participants in this study recall some amount of discomfort in response forced discussions about sex in the school setting, the contrast of male and female participants' responses to this awkwardness are illustrative of their experiences with cultural gender norms regarding open conversation about sexual experience or demonstrating interest in sex.

As was clear in participants' accounts, the shame and embarrassment associated with adolescent female sexuality clashes with sexual information sharing intended during sex education, causing many women in this study to remain silent, to shy away from their 
questions and to sometime experience emotional distress. Molly remembers intense emotional pain during her sex education class when hearing sexual scripts that devalued her personal sexual experience. She laughs when asked about the emotions she felt during her sex education program and says "so yeah I felt like shit". Molly remembers:

I became sexually active when I was fourteen and so that was--it was definitely applicable to me at the time. I actually, in that health class is when that relationship ended. And I felt absolutely horrible about myself like, had a hard time going through the rest of the class because it was like "I had sex with this person that I loved and now he has broken up with me and what does that say about me?"

Molly remembers sitting silently, as she internalizes new meaning assigned to her sexual experience. Previous work on adolescent female sexuality has illuminated some of the psychological and social effects that differential access to sexual scripts have on girls as they develop into adults (Fine 1988; Tolman 2002). Sociologist Deborah Tolman (2002) observed "disassociation" in the teenage girls she interviewed when discussing their experiences of sexuality. Tolman argues that the fear associated with sexuality that teenage girls experience as they learn the sexual scripts available to them can cause them to disassociate "from their authentic thoughts and feelings" (2002:54). Several female participants in this study describe this feeling of disassociation as adolescents. They remember feeling distant from their own understandings of sexuality and shut down when learning about sex in the sex education classroom, as they experience difficulty thinking of themselves as sexual beings. Tori, a female participant in her late teens remembers: "I didn't remember thinking 'Oh this is something I will need to remember.' It seemed, I mean as much--this may be an odd word to describe an 11-year-old, but I felt kind of detached from it in a way." In Tori's case, she resolves the discord between her emerging 
sexuality and the scripts available to her as a teenage girl by "detaching" and distancing herself from the conversation in the sex education classroom.

Other female participants remember a "detached" feeling, as they struggled to process their sexuality in the context of sex education without the language or script to affirm their sexual experiences and feelings as teenage girls. Other research has argued that having the language to affirm one's identity, and importantly a sexual identity is a form of power (Laws and Schwartz 1977; Tolman 2002). Lacking a sexual script that affirms their sexual desire, teenage girls fall victim to a sexual power imbalance that develops into the inequality inherent in adult masculinity and adult femininity. Julia, a female participant in her early twenties remembers her feelings about sex during her experience with sex education in school:

I mean it was a very scary idea to me originally. They kind of, everybody made it sound very scary like you know "there's this horrible thing that happens and we don't talk about it" sort of thing. You know, I think I expected something awful to happen when it eventually happened. I was very scared of it and my own sexuality so I just ignored it until later on.

The absence of a script that affirmed her sexuality, as experienced by Julia left her with fear surrounding sexual activity and discouraged her from processing or exploring her sexuality in adolescence, a feeling she says was reinforced by her sex education program.

Importantly, some participants in this study also recounted the feelings associated with lacking a script that affirmed any non-heterosexual identity. Abstinence-only sex education curriculum has also been widely criticized as heteronormative (Elia and Eliason 2010; Fields 2008; McNeil 2013). As is noted in the previous chapter, eight out of the 20 participants in this study do not identify as heterosexual. Several these participants who identify as pansexual, bisexual, queer and gay remember hearing 
heteronormative messages about sex during their sex education experiences. Crystal, a pansexual female in her late twenties remembers "that anyone would be gay was just unimaginable and that was just totally not part of the conversation." As remembered by Crystal, her sex education program represented only a heterosexual perspective without any consideration of alternative perspectives or experiences of sexuality. As described by several participants, messages about sex in sex education were limited to heterosexuality, making up a script that described sexual behavior solely on those terms.

\section{Discussion}

The sexual scripts available to teenagers generally, and differential scripts available to teenage boys and teenage girls have been explored through the experiences of the participants in this study with sex education in school. Sex education in school is an important place to explore cultural sexual scripts because its content and form is influenced by the immediate social and political context (Hartley and Drew 2002). Teenage sexuality is scripted culturally as dangerous, as is illustrated through the narratives of both men and women in this study. In response to social concerns about risky teenage sexual activity, sex education can act as an intervention measure, emphasizing the physical consequences of irresponsible sexuality, like STD transmission and pregnancy. Additionally, information about sex communicated to teens is limited to heterosexuality, as remembered by participants in this study.

Access to sexual scripts for men and women diverge at this juncture. The sexual scripts in sex education available to teenage boys define male sexuality as natural, expected and active. More men than women in this study remember hearing from 
teachers that what they were feeling sexually as adolescents was 'normal' and that they were expected to be eventually sexually active. Masculine sexual desire and activity was affirmed through messages in sex education.

For many women in this study, sex education classes were a conduit for cultural norms regarding feminine sexuality. Female participants remember hearing messages about the social consequences and dangers of their sexuality as adolescents in sex education. For these women as teenagers, sexual activity and feelings included repercussions like being seen as unfit for future male partners, disappointing family, and harm to one's reputation and social status. Some women remember hearing messages encouraging them to be sexually defensive and alert. These findings are consistent with other studies of adolescent female sexuality (Fine 1988; Tolman 2002). Some women in this study also expressed feelings similar to the "silence and disassociation" of the teen girls in Tolman's (2002) formative study. When learning about sex in school, teenage girls are left without scripts that affirm their sexual feelings and experiences.

Using sexual script theory (Gagnon and Simon 1973) as a framework, the narratives of the participants in this study illustrate the ways that sex education plays an important part in the sexual socialization of adolescents as they transition into adult sexuality. Messages about the dangers of teenage sex reflect the cultural 'moral panic' of the time, and the sexual scripts differentially available to teenage boys and teenage girls in sex education reproduce sexual power imbalances inherent in dominant expressions of adult masculine and feminine sexuality. Clearly, sex education is not the only place adolescents learn about sex and it is often not the more important location of sexual learning either. Deeper exploration of these sexual scripts as experienced by participants 
from other sources in their lives give a more complete picture through which to understand gendered sexuality, inside and outside of the sex education classroom. 


\section{CHAPTER 5: SEXUAL SCRIPTS AND INFORMAL SEX EDUCATION}

In addition to school-based sex education programs, previous literature has named several important sources of sexual learning for adolescents, most prominently the family, peer groups, religious communities, media, and the internet (Bleakley et al. 2009; Somers and Surmann 2007). From these sources students learn things about sex that may be in conflict or agreement with school based curriculum. While sex education in the classroom is relatively controlled, involving one teacher and a group of captive student learners, other more informal sources of sex education are dynamic and interactional. This chapter explores the sexual scripts made available to men and women from these more informal sources, in comparison with messages learned in the classroom. As explored in the previous chapter, gender norms are foundational in sexual socialization, and an exploration of the sexual scripts available to the men and women can inform understandings of gender differences in sexual behavior and attitudes in adulthood.

\section{Experiences with Informal Sources of Sex Education}

Narratives of informal learning about sex indicate that the sexual scripts drawn from participant's accounts are made available in both similar and different ways when compared with the sex education classroom. The danger script made up of danger-based messages that warn teens of the physical dangers of sex is communicated to teens in general from their families, but is generally missing from conversations about sex with friends. Participants' accounts show that the traditionally masculine desire script that affirms emerging sexual feelings and the agency script that describes individuals as sexual actors are still accessible to teenage boys from their families and peers, but 
interestingly, the narratives of female participants also reveal ways that the agency script was communicated to them by their mothers. Facing scripts about the dangers of sex from their families and teachers, several accounts of male participants reveal a counterscript constructed in peer groups: the risk-taking script that scripts sexual risk taking as a demonstration of masculinity. The sexual scripts available to teenage girls in formal sex education programs that warn them of the social consequences of their sexuality and describe teenage girls as sexual gatekeepers are still emphasized by family and peer groups. However, important gender differences in communication patterns that influence what and how much is learned about sex in the family, peer-groups and online must be noted. Through the narratives of the men and women interviewed for this study, the sexual scripts communicated to them from informal sources of sexual learning are explored. As was the case with school-based sex education programs, participants' narratives in this study offer interesting information about the form and content of more informal sex education experiences.

\section{Gender Differences in Family Communication}

Participants' narratives in this study offer interesting information about the family as a source of sex education. A most important source of socialization in general, many participants reported learning something about sex from their families, although the depth of conversation and messages varied. As was detailed in the literature review section, previous research has indicated important gender differences in family communication about sex. Studies conclude that sons have less conversations about sex with their parents than do daughters (Epstein and Ward 2007; Jaccard, Dittus and Gordon 2000; Nolin and 
Petersen 1992; Sneed 2008). This phenomenon likely occurs because mothers usually take on the role of sex educator in families, and both parents and children feel more comfortable with same-gender sex talks (Nolin and Petersen 1992, Sneed 2008). These findings are consistent with participants' narratives in this study, and while most participants reported some level of discomfort talking about sex with parents in general, a majority of female participants remember less discomfort and more open conversations, especially with their mothers in comparison with few men.

Sons often sense discomfort from their parents or come to an understanding that the subject is off limits. Mothers and sons may experience discomfort motivated by gender and sexual differences, leaving conversations limited and strained. This can mean that sexual information is sought from other sources, like the media or from peer groups (Epstein and Ward 2007). Jake remembers communication with his mother about sex:

As far as my family goes, that was a conversation my mother and I never had. I don't think her and I ever had a sex conversation until I went home and I was like "hey, my girlfriend's pregnant. And she needs to come and live with us now." I don't think a conversation was had before that, and I was eighteen years old so a long time.

Jake's story illustrates how conversations about sex between mothers and sons may be evaded until they become unavoidable due to unexpected outcomes like pregnancy. While sex education between parents and sons is sometimes avoided due to discomfort, parents may also have fewer restrictions regarding their sons' sexual behavior. The gendered cultural understanding that the consequences and risks associated with male sexuality are much fewer in comparison with female sexuality may have influence on parents' motivation for conversations with their sons about sex (Nolin and Petersen 1992). Jake remembers the conversation he had with his parents as a teenager: "They 
kind of figured that I knew about it on my own. Like there was never a real sit down talk. They were just like 'do you have condoms?' Like if I was going out with a girl they were just like 'do you have condoms?' and I was like 'yeah.' 'Cool, great.' You know, 'try not to destroy the town'". These gendered patterns of communication, resulting in few parent conversations about sex for male participants in this study, shape the sexual scripts communicated to them in the context of their families.

In contrast, seven out of the ten women in this study remember having conversations about sex with their mothers that they recall as "open" and "honest". These conversations were often about safety and healthy relationships, and gave these women access to information they did not feel they had access to from other sources as adolescents. Taylor remembers her conversations about sex with her mom: "I am really close with my mom so any questions I can just ask her...yeah, she was really sweet about it." A majority of women in this study echo this sentiment regarding their mothers, feeling that their conversations were safe and helpful.

While most of the female participants in this study describe their mothers as an important source of information and support, these women remember these conversations as nuanced, often including conflicting messages. For women, open discussions about sexuality and sexual interest or experience have traditionally been taboo (Laws and Schwartz 1977) and the narratives of the women in this study also illustrate this cultural tension embedded in mother-daughter talks about sex. Audrey remembers the back and forth she experienced with her mother:

And my mom was always the person to be like "I will answer any question you ask me, in detail." So that was a fun experience and I think in general my first, first learning about everything was from my mom because she created an 
environment where it was okay to ask questions but at the same time she's also from a conservative background so it's--only so far would she answer the questions before she was kind of off put like "that's not appropriate." So like she would answer anatomy questions, she would answer factual questions but at some point she would be like "well, that's--don't do that."

Audrey's story reflects the cultural strain women can feel talking about sex, as her mother responds to some questions, but not others and clearly defines the limits of appropriate sexual interest. An added level of complexity, several of the women in this study remembered the way their mothers navigated the tension of openly talking about sex with their daughters in private, while encouraging them to keep these talks discrete in public settings. Julia recalled an experience like this while attending a private, Catholic school. Julia and her mother talked openly about sexuality in their home, but when at school Julia experienced more restrictive attitudes. Julia said of this experience:

Julia: Like I said I was always sort of doubting it. And I would talk to my mom and she would be like "You know just go along with it. You're at school where the people think a certain way, especially since you're in a very conservative school. I don't want you to get thrown out." So I mean I would go home and talk to her about it and the things that bothered me. And I think I just sort of had two different ideas where I would say one thing and then think another way.

Elizabeth: Was that difficult at all?

Julia: It was a little bit difficult. It was very conflicting.

Julia's mother negotiates a way to support her daughter, while avoiding the social consequences of an open sexual dialog by encouraging Julia to "just go along" with the more repressive attitudes at her school. These narratives are reflective of the findings of Sinikka Elliott's (2012) interview based study, in which she documents the confusion and ambivalence parents often feel as they both deny the existence of and negotiate sexuality in the lives of their teenage children. 
As in Julia's case, previous research has shown religious affiliation to have influence on how families communicate about sex. Researchers Tamara D. Afifi, Andrea Joseph, and Desiree Aldeis (2008) found in their qualitative study of parent-child communication about sex that parent religiosity meant fewer conversations about sex in the home. These more religious families advocated for abstinence, and kept conversations about sex brief because parents felt "sex wasn't an issue" in their children's lives (2008:717). The minimal conversations that were had by religious parents tended to be regarding sexual values and morality, a finding consistent with the accounts in this study. Five participants in this study reported growing up in a religious family or community. Lisette's narrative illustrates the impact religion had on her parents' communication about sex: "[They are] conservative Christian so they said sex is for marriage. Be abstinent, take this abstinence pledge. That was it." She goes on to describe the abstinence pledge initiated by her parents

My parents got me a ring when I was sixteen that was like--it came with a card that was "I won't have sex until I'm married" and I don't know if they kept the card or if I kept the card, or what happened to it. But like basically saying I won't have sex until I'm married and I will marry a nice Christian man in a nice white Christian church and it will all be non-messy and clean.

Lisette's story is an example of how religious attitudes can limit conversations about sex in the family, keeping the focus on sexual morality and waiting for marriage.

Participant's narratives in this study illustrate how sex education, and subsequently the sexual scripts communicated within the family can be influenced by gender, often meaning that sons get little communication from parents about sex. While mother-daughter conversations about sex are more frequent, more open and in depth, female participants also recall the tension and conflict inherent in their sexual learning as 
adolescents. Some mothers kept conversations limited to what they deemed was "appropriate" for their daughters, and some navigated cultural attitudes about teenage female sexuality by letting their daughters lie to outside sources about attitudes and behavior. Several narratives in this study also supported previous research showing the way that religiosity can limit family communication about sex. For those who received little sexual information from their families, learning from other informal sources like peer groups proved to be especially salient.

\section{Gender Differences in Peer Communication}

Gender differences in peer-group conversations influence what and how much adolescents learn about sex from their friends, and thus shape the sexual scripts communicated in these groups. While they learn very little about sex from their families, men report learning more about sex from peers as teenagers than from any other source (Epstein and Ward 2007). The findings of this study are consistent: all 10 male participants recall talking extensively with peers about sex. When asked what he learned about sex from his friends, Caleb responds: "Everything. Everything. Can I expand on that? [Laughs]. I mean, you know just everything. Everything from masturbation to foreplay to having sex. Just everything. You know, I couldn't get it from my family.” Here, Caleb talks about seeking information from his friends, information he couldn't get from his family. Sexual information sharing is an important practice among male peergroups (Flood 2008), as they affirm experiences and demonstrate their sexual interest while also gaining sexual knowledge (Epstein and Ward 2008; Flood 2008; Kehily 2001; 
Pascoe 2007). The peer-group conversations remembered by the men in this study illustrate these dynamics; sexual knowledge and storytelling are central themes.

The men in this study recall their peers groups as important sources of sexual information, and simultaneously, they remember the way that sharing sexual information formed and solidified bonds in these peer groups. Most of their narratives include memories of telling sexual stories, advising each other on initiating sex and sharing pornography among friends. When asked what he learned about sex from his friends Jonah like Caleb, says "probably most of it." Jonah expands on some of his early memories learning about sex from his peers:

I remember when I was really little we would like lock the door in the front room and we would look up booby pictures together. There would be like three or four dudes looking at booby pictures. It was just like a thing that we did... when you're a kid and everyone is curious at the same time, you know we kind of poke around and stuff like that. So definitely I think I learned most of it from my friends and got my initial experiences as far as, definitely pornography is concerned and just general like "this is the way that you should do it" kind of technical advice, I guess.

Jonah describes open communication about sexuality among his peers at a young age including sexual topics ranging from curiosities to "technical advice". Examples like Jonah's story that include viewing pornography and sharing curiosities by "poking around" in homosocial groups illustrate this performative nature of sex talk for men.

In stark contrast, previous research that conversations about sex in female peer groups tend be much more limited and heavily policed (Chambers, Ticknell, and Van Loon 2004). Several women in this study remember some conversation about sex with friends, but five out of ten female participants also recall some level of discomfort and ambiguity inherent in these conversations. In contrast to the openness experienced by 
male peer groups, some women, like Crystal, remember vagueness and policing. Crystal recalls about conversations with her friends: "Like lots of euphemisms, rather than scientific terms--which I have always been a fan of the scientific terms and the scientific approach. And just that kind of sense of like 'that's dirty and if you talk about that you are a lower form of human.' You know, 'you're trashy, you're slutty.'”. In Crystal's story, she experiences policing and learns little about sex or sexuality from her femalepeer group.

\section{Gendered Differences in Sexual Learning Online}

As was detailed in the literature review section, research indicates gender differences regarding what adolescents learn about sex online (Hald 2006; Leiblum 2001; Mesch 2009; Ybarra and Mitchell 2005). These studies find that online pornography seekers are overwhelmingly male (Ybarra and Mitchell 2005). This gender gap is supported in this study in that all 10 male participants recounted learning about sex through pornography, in comparison with none of the female participants. These high consumptions levels, documented by previous research and reflected in this study equal important sexual learning differences that may contribute to the sexual scripts available to men and women. Jonah remembers learning about sex from pornography in his adolescence:

I started watching [pornography] when I was twelve, you know like religiously when I was twelve. So for many, many years it was interesting because I didn't have sex probably until I was fifteen or so--probably in that area, I don't really remember. But there was three years of only pornography as my means of knowledge. So I feel like I was actually kind of experienced because I had seen visually so many different ways or techniques or whatever you want to call it. So 
when I was able to, I kind of had a general idea just no practice. So, albeit sloppy I felt like I was, you know, skilled. That's basically--it just taught me what to do.

Jonah's narrative illustrates one reason research indicates men look at pornography: sexual curiosity (Albury 2014). Pornography consumption by men may be motivated by pressures to be sexually knowledgeable and experienced, norms integral to traditional masculine sexuality pornography can act as a source of this knowledge for the unexperienced. Pornography can allow men like Jonah to feel knowledgeable, experienced and "skilled" in preparation for partnered sex in adolescence. Previous research has framed (legal and non-violent) pornography consumption as a source of sex education, potentially leading to "increased pleasure, self-acceptance.... in addition to the widening of traditional gender roles and sexual scripts" (Doring 2007: 1094). However, it is important to note the associations drawn between mainstream pornography and the objectification of women's bodies, sexist beliefs and negative attitudes towards women (Stulhofer 2010). Male peer groups are often the intended audience for sexual experience and knowledge gained online, and pornography consumption must be demonstrated in conversations with friends as a performance of masculinity. Ben remembers discussions about pornography among his friends in school:

Because I remember having conversations with my friends about what porn was the best... and this kid named Josh and me were talking and all the other boys and were like "oh you know, Asian pussy that's the best." [Laughs]. And we like we knew anything about it, like "yeah, yeah I agree." [Laughs]. It was like "oh yeah, that's--yeah I will keep that in mind."

Ben's story illustrates the importance of affirming interest and experience with pornography in his friend group, even if his interest and experience is bluffed. Ben's narrative also offers an example of the racialized objectification of women's bodies 
mainstream pornography can perpetuate, and indicates a need to remain especially critical of the role pornography plays in male peer group conversations about sex, and communication of the desire script (Shimizu 2006).

While pornography consumption, especially online, serves several purposes for teenage boys as they learn about and explore sexuality, in contrast, none of the women in this study recounted experiences with pornography when asked what they learned about sex from the internet. Instead of seeking pornography online, research indicates that women most frequently use the internet to access email, chat groups and discussion forums (Leiblum 2001), reflecting cultural attitudes about femininity that script women as relational, instead of sexual. Sexual scripts communicated in sex education, from their families and in their peer groups script interest in sex as deviant for women, and may in part explain the online gender gap. In this study, some female participants remember tension and embarrassment when using the internet as a source of sexual information. Molly recalls:

For a while I don't think I felt comfortable enough. Like I was afraid that I would leave something up on the screen or the next person would go to search in google and it would show in the little drop down menu of your recent searches like learning about a yeast infection or something, that I would--and I didn't necessarily like typing it out, and writing those words makes it concrete.

Although women like Molly experienced anxiety regarding the clash between cultural femininity and sexual learning online, some researchers are hopeful about the ways that the internet will benefit women, allowing them access to information they can use to process and affirm their sexual identities. Sandra Leiblum writes "For young women who tend not to raise questions in traditional classroom settings, the internet provides a safe, anonymous and protected place for admitting ignorance and raising concerns" 
(2001:394). Several women in this study remember the internet as a positive space, where they were able to connect with others, and seek information sheltered from social pressures. Audrey remembers the purpose the internet served for her:

I joined a couple of online forums that were sex positive forums and just people talking. Obviously I had to lie about my age a little bit which was bad...but if a had a question I could ask it or I could find somebody else asking a question and be like "oh that's interesting" and learn about it that way. So it was kind of really good community to learn from so to speak. That's kind of how I got my education is just learning from other people so it was kind of a safe environment.

Audrey's narrative indicates the way that some women in this study used the internet to learn about sex through chat threads and forums, in contrast to ways that the internet was used by the men in this study for sexual learning. These gender differences in online communication, as well as differentiated patterns of communication in the family and in peer-groups indicate a level of complexity not present in the sex education classroom. These gendered patterns add nuance, and influence the ways that sexual scripts are communicated from these more informal sources of sex education.

\section{Revisiting Sexual Scripts}

With these important structural considerations regarding these more informal and dynamic sources in mind, the sexual scripts developed and referenced in the previous chapter exploring school-based sex education are revisited and analyzed. Drawn from participants' accounts, the sexual scripts made available to teenagers in their families and in peer-groups mimic and differ from those recalled from sex education in content, although they are presented to men and women in different ways. These sexual scripts include the danger script consisting of danger-based messages that warn teens of the 
physical dangers of sex, the desire script affirming the subjects' emerging sexual feelings, and the agency script scripting individuals as sexual actors, capable of their own sexual decision making. Several accounts of male participants reveal a counter-script constructed in peer groups: the risk-promotion script that scripts sexual risk taking as demonstration of masculinity. The social consequences script describes sexuality as having social repercussions like a damaged reputation and the gatekeeping script which scripts the individual's role as defensive and responsible for boundary setting in sexual relationships. Through the narratives of individuals interviewed for this study, these scripts and their availability informally to male and female participants are explored. 
TABLE 4: SEXUAL SCIPTS IN THE FAMILY

\begin{tabular}{l|ll}
\hline Script & Men & Women \\
\hline Danger & Kevin, Julius, Howard, John & Molly, Audrey, Kelsey \\
\hline Desire & Cameron, Julius, Jonah & Audrey \\
\hline Agency & Kevin, Ben, Jake & $\begin{array}{l}\text { Molly, Julia, Crystal, Stephanie, } \\
\text { Taylor }\end{array}$ \\
Risk-taking & & \\
\hline Social Consequences & John & Molly, Lisette, Taylor, Audrey \\
\hline Gatekeeping & & Courtney, Kelsey, Tori, Taylor \\
\hline
\end{tabular}

TABLE 5: SEXUAL SCRIPTS IN PEER GROUPS

\begin{tabular}{l|ll}
\hline Script & Men & \multicolumn{1}{c}{ Women } \\
\hline Danger & $\begin{array}{l}\text { Cameron, Julius, Jonah, } \\
\text { Ben, Wayne, Caleb } \\
\text { Howard, Jonah, John, Ben, } \\
\text { Wayne, Caleb, Jake } \\
\text { Caleb, Jonah, Jake, Howard }\end{array}$ & \\
\hline Agency & \multicolumn{1}{|c}{ Molly, Crystal, Kelsey } \\
\hline Risk-taking & & \\
\hline Social Consequences & & \\
\hline Gatekeeping &
\end{tabular}

TABLE 6: SEXUAL SCRIPTS AND THE INTERNET

\begin{tabular}{l|ll}
\hline Script & Men & Women \\
\hline Danger & & Audrey, Crystal, Kelsey \\
\hline Desire & $\begin{array}{l}\text { Kevin } \\
\text { Kevin, Howard, Jonah, Ben, } \\
\text { Wayne, Caleb, Jake, }\end{array}$ & Crystal, Courtney, Kelsey, Tori \\
\hline Agency & \multicolumn{2}{l}{} \\
\hline Risk-taking & & Molly, Courtney \\
\hline Social Consequences & & \\
\hline Gatekeeping & & \\
\hline
\end{tabular}




\section{Danger Script}

The danger script, as defined in the previous chapter, is used to communicate that sexual activity is potentially physically dangerous, especially to those engaging in irresponsible sexual behavior. In the same way that school-based sex education can be seen as an intervention measure, meant to curb uninhibited sexual desire and regulate risky teenage sexual activity (Carpenter 2005; Fine 1988), family-based sex education may be motivated by parent perception of risk. The danger messages about sex and its physical risks were a common theme in both male and female participants' narratives regarding conversations with parents about sex. In this way the danger script identified in participants' remembrances of sex education in school is mirrored in informal sex education experiences within the family.

The danger script scripts sexuality as potentially harmful to those who engage in it, and emphasizes its physical risks. Participants' families are embedded in the cultural 'moral panic' surrounding teenage sexual activity, and conversations regarding sex are often motivated by concern (Bay-Cheng 2003). For seven out of twenty participants in this study, this danger script was communicated to them by their parents, stemming from concerns regarding adolescent sexual activity. Kevin remembers the central message from his mother's discussion with him about sex: "She was okay about it, she was just like 'use protection and know that there's dangers in doing it.' So she went through all that. That would be like middle school. With her, giving those examples." As remembered by Kevin, the dangers involved with sexuality were the central message of his mother's communication with him about sex. 
The danger script as communicated by families was not necessarily gendered;

three women and four men remembered danger messages of this kind. Similar to the danger messages central to school-based sex education, the danger script communicated in the family focused on physical risks like STD transmission and pregnancy as repercussions of teenage sexual activity. Audrey remembers learning about sex from conversations with her mother:

So that was kind of brought up at some point of like "be really careful and don't-if you are going to have sex make sure its protected" and that's another reason why she fought me going on birth control for so long because she thought that if I was going to have sex that she wanted it to be protected and protected with condoms not just with birth control. So she was very afraid to put me on the pill and have me be like "oh, now I don't have to use condoms!" That was pretty obvious in her fears. Like she didn't specifically say that, but she was like "no, I don't think--I'll buy you condoms if you want but I'm not going to put you on the pill. I don't want you to just wildly have sex with anybody." So, I got that vibe. Just kind of fear based, from her past of having friends die from that.

In Audrey's story, she remembers sensing that her mother's communication with her about sex was motivated by fear. Audrey's mother uses the danger script by emphasizing the dangers associated with unprotected sex, in hopes of mediating her daughter's risk while using hormonal birth control. In contrast to the family setting, the danger script was a rare theme in conversations participants remember having with peers about sex. Only Audrey, remembers discussing concerns about the physical dangers of sex with her friends. She recalls consoling a friend frightened by the possibility of acquiring HIV/AIDS.

Risk-Taking Counterscript 
Discussions of the dangers of sexuality were largely missing from conversations about sex among peer groups, and while women recall limited conversations about sex in general among their peers, some men in this study recount a counter narrative constructed during their extensive sexual conversations in their male-peer groups. In illustration of the danger script's absence, Jonah remembers differences in the ways that he and his friends talked about sex, in comparison with school-based sex education:

I mean, because there's school which is "this is what you're not supposed to do." And then there's friends which is "this is what you should do because it's cool. Or it's really fun." Or whatever, you know. There's no negative things. Your buddy's not going to say you know "oh man, I got herpes from this girl." There's no way he would tell me that. Unless we were like really, really close. So I mean there's just, when it comes from your friends, everything is positive.

Like Jonah, most male participants in this study recall danger scripts from their families and sex educators that described teenage sexuality as dangerous and remember that abstinence and contraception use were promoted as ways to minimize the risks associated with teenage sexuality. While learning about the dangers of sex as teenage boys, two of the ten male participants in this study also remember adopting a counterscript that allowed them to embrace the risks of sex through the rejection of safe sex practices. Psychologists Donald Tomkins and Silvan Mosher write that an essential component of the sexual script culturally available to men is to view "danger as exciting" (1988:60). As argued by Mosher and Tomkins (1988), risk taking and danger are cultural characterizations of masculinity and while adolescents received messages about the dangers of irresponsible teenage sex, some respond by adopting a counter-script, or rejecting protective measures that would mitigate the risks associated with sexual activity. This resistance to protective measures like contraception as an act of masculinity 
has been documented in previous research (Noar and Morokoff 2002), and is described by several male participants in this study. For a few men in this study, this counter-script develops in contrast with the danger script communicated by parents and sex educators.

Howard, a male in his mid-twenties demonstrates this during his interview:

Elizabeth: Do you remember feeling that any of that information during sex ed about being sexually responsible was important to you personally?

Howard: No. Not at all. I mean, I do remember being sexually active around that age but I don't remember ever needing, or feeling like I needed to use a condom or anything like that. I knew about them but I just--I don't know, they didn't feel good or other people would tell me "it's better without condoms." And I was like "okay."

Howard remembers learning about protective measures that would mitigate the risks of teenage sexual activity in sex education, but also remembers his peers encouraging him to dismiss these danger messages. This resistance to contraception or other safe sex practices, in favor of risk-taking, is an aspect of the sexual script culturally available to men developed in adolescence.

While Jonah remembers a similar experience regarding the rejection of safe sex practices, like condom use, his account of the risk-taking counterscript also emphasizes the peer pressure associated with sexual risk taking. Friends are described as encouraging each other to take sexual risks like condom-resistance but also to disregard instructions about sexual boundaries and respect learned in school. Jonah goes on to describe the dynamic in his male peer-group:

You know like a lot of times they goad you on to it. They are like "do it, just do it man. Just do it." Or if you didn't do something that you should have done, they give you a hard time about it...You know, so they give me a hard time for not doing something that I didn't do. So there's an entirely different sort of ballgame. You know, in class they teach you about respect. Well one of my friends is like "just do it anyways who cares." So there's that almost peer pressure, but you 
know they wouldn't really force me to do it but they are like "you should have because the story would have been better."

Jonah's story shows how this script is constructed among peers, specifically in contrast to school-based sex education in his case where they "teach you about respect." Risk-taking is a rewarded behavior embedded in the sexual script available to men, and narratives of several male participants demonstrated how teenage boys sometimes adopt a counterscript to the sexual responsibility discussed by families and sex educators and embrace the dangers associated with unprotected sex.

\section{Desire Script}

As was the case for many male participants' narratives about sex education, affirming adolescent sexual desire as natural and expected was a central aspect of the sexual scripts available to men from their families and peer groups. Although conversations between sons and parents were limited, the desire script was a theme in these conversations, as reported by three male participants in this study. Jonah describes a conversation with two of his male guardians in illustration of the desire script communicated to him as a teenager:

The dads, it was different...you would go out with them, probably when I was around twelve and thirteen and they would be like "oh look at that girl." You know, they start to show you what a pretty woman looks like or this that and the other thing. You know, not like the movies say this lady's pretty but they are going out and pointing them out to me. So they are giving you this personal aspect of it.

In Jonah's narrative, his father-figures encourage and affirm his sexual interest in women's bodies. This personal interaction allows Jonah access to the desire script in a very real way, giving him a tool with which to ascribe meaning and appropriately direct 
his sexual feelings. Despite the fact that many more female participants report talking with members of their families openly about sex, only one out of ten women in this study remembers hearing the desire script communicated to her in the context of her family.

Peer groups have been established as a place of much sexual communication and learning for men. In peer groups, men bond through sexual storytelling and construct heterosexual identities by exaggerating and affirming their interest in women (Epstein and Ward 2008; Laws and Schwartz 1977; Pascoe 2007). The desire script was remembered by six out of ten men when recalling conversations about sex with their peers. This is in comparison with no female participants; a finding that is consistent with the literature. Culturally for teenage girls, interest or desire is considered deviant (Laws and Schwartz 1977; Tolman 2002; Wiederman 2005) and conversation within female peer groups is limited and policed (Chambers, Ticknell and Van Loon 2004; Laws and Schwartz 1977), leaving no room for communication of the desire script. For men in this study, sharing sexual curiosities and discussing and circulating pornography was an important part of sexual socialization. Cameron has a typical narrative illustrating the desire script:

As a guy? We talked about sex a lot. You know, younger--let's see like I said, I probably didn't get into it until I was a junior or senior. And that was like, friends with pornography magazines and you know looking at women, naked women. Talking about you know, what we would like to do sexually. But that came later, yeah that was like hormonal stuff.

Cameron's narrative illustrates the way that his male friends shared and affirmed one another's sexual interest and desire. This desire script made exclusively available to male participants in peer-groups indicates its importance for the construction of masculinity in adolescence. 
Agency Script

The agency sexual script describes individuals as sexual actors and acknowledges that they are or will be sexually active, as was demonstrated through participants' remembrances of sex education in school. Recounted largely through male participants' experiences with sex education, this script draws on the cultural assumption that sexual activity is expected and often rewarded for men (Wiederman 2005). Even though men report learning less about sex from their families than do women, the agency script is still remembered by three out of ten male participants in this study. Ben remembers being treated by his family as a sexual actor, capable of his own sexual decision making:

Firstly I knew that I didn't want to have sex early on and I knew that my family would support me no matter what. So that was always what I had in my mind. So I didn't want to but if I did, my family would be there, they wouldn't be happy with me but they would be there. I mean that was even conversations that I had with my parents. Not that I was planning to, but you know things come up.

Ben's account indicates the way he was treated as a teenager by his family: as responsible for his own sexuality, whether he chooses to be sexually active or not. Parents communicate this script in a way similar to sex educators, giving caution about risks, but assuming that teenage boys will eventually and inevitably be sexual. This "boys will be boys" discourse contributes to the development of sexual agency, as teenage boys learn that they are expected to be sexually active. Jake remembers his parents' attitude about sex, who let him take the lead in his own sexual decision making:

I think it's always been indifferent. Just kind of like "it happens." You know, because I grew up from a--they were both religious but they didn't force me to be religious so it's very interesting like, they just let me do what I want...they just kind of let me explore. So, it's the same way with sex. It was just kind of like "well, this is a thing." 
Jake remembers feeling a similar support as did Ben; he remembers that his sexual exploration was entirely up to him, and he could expect his parents to respect his sexual decision making.

As detailed above and in previous research, parent-daughter communication about sex is usually more frequent and extensive than parent-son communication (Epstein and Ward 2008; Jaccard, Dittus and Gordon 2000; Nolin and Petersen 1992; Sneed 2008). This could be due in part to increased comfort provided by same-gender parent and child conversations (Nolin and Petersen 1992). Previous research indicates that mothers have historically been the primary sex educators in the family context, mostly initiating conversations with their daughters about sexuality (Nolin and Petersen 1992). An important divergence from the sex education classroom where women were generally denied access to the sexual agency script, five out of the ten women in this study remember this agency script being communicated to them through conversations with their mothers. Crystal remembers a conversation with her mother that encouraged her to think of herself as a sexual being:

She was like "One day you are going to be a sexual being and that's healthy and that's what you should be doing." Ostensibly, I mean. I guess she would have still loved me if I was asexual but you know she was like "That's probably going to be a part of who you are, that's going to be part of your life and I want you to have a good understanding of what that means. So if you have any questions ask."

In this study, women like Crystal who had access to the agency script remember being treated as capable, and responsible for their own sexual decisions. As part of this agency script, being sexually active was affirmed as their choice to make. Stephanie remembers the central message of a conversation about sex with her mother: "My mom was really open about it. She was like 'if you ever want to have sex just let me know I will take you 
to the doctor, get you on the pill. Just let me know'." In conversation with her mother, Stephanie is made to feel that she is in control and can choose when and if she wants to become sexually active with her mothers' support.

Mother-daughter communication like that experienced by Stephanie was often motivated by mothers' personal experience, as remembered by participants. Mothers who lived the cultural taboo of discussing sexuality as teenage girls were conscious of the negative consequences of not having access to sexual information. Taylor recalls why her mother made an effort to talk openly with her about sexuality:

Obviously, my mom and I-- really close. She just talks about it a lot. She was one of six and she didn't get a sex education in school or from her mom, my grandmother. Her mom--my grandmother was like a hands-off grandmother so she didn't get that full rounded thing of talking about it or feeling comfortable enough to go to her and talk to her about it. And she got married at nineteen and divorced at twenty one.

The openness Taylor benefitted from was seen as her mother's attempt to better equip her daughter in contrast to her own past experience. Although denied access elsewhere, female participants remember the agency script being made available to them through conversations with their mothers, an experience they recount as important to developing healthy sexual identities.

The sexual agency script is communicated in male-peer groups in a way similar to the desire script. Being sexually active and demonstrating this sexual activity for malepeer audiences is central to the construction of the masculine identities of teenage boys (Flood 2008; Pasco 2011). Researcher Michael Flood explored the "homosocial organization of men's heterosexual relations" through a qualitative analysis of communication between teenage boys in school. Flood finds that "sexual activity is a key 
path to masculine status, and other men are the audience, always imagined and sometimes real, for ones' sexual activities" (2008:342). When talking about sex with friends, detailing sexual activity and experience, and making use of the sexual agency script, can be foundational for constructing and maintaining masculinity. The agency script is central to the conversations in which teenage boys learn about sexuality from their peers. Seven out of the ten male participants in this study remember the agency script being communicated during conversations with peers about sex, including Ben, who remembers what he learned from his friends:

Maybe with misinformation sort of thing. Like how a girl gives a blow job...You know, things which maybe were wrong at the time. Like how you should feel or what you should do to initiate, just silly dumb things that sometimes might work out.

In this instance Ben remembers being scripted as the initiator among his friends, reinforcing his sense of agency as the sexual actor. Sexual agency as remembered by some male participants was at such a high value among homosocial peer groups, that talking about sexual activity could increase social status. Jonah's narrative illustrates this with a memory of his friends in high school:

And then as I got older, I remember there was this buddy of mine--he's one of my best friends now, we were-- I started [having sex] pretty early and he started early so we were like--we knew a lot that no one else did. So we were able to have conversations and that was actually one of the reasons we became good friends because we both had strength training class together and we basically talked about girls, chicks and sex the entire strength training class. So we had that connection and then as more people kind of grew into it and had sex on their own, they would kind of join our group.

Jonah remembers his own sexual activity as a bond between a friend and him, and illustrates the status associated with sexual activity among his peers, as others "join the group" upon becoming sexually active. A sexual double standard is reflected here in the 
finding that no women in this study recount the sexual agency script in conversations with their female peer groups. Sexual agency, sexual aggressiveness, and the initiation of sexual activity are all scripted as deviant experiences of sexuality for teenage girls (Wiederman 2005). While for men like Jonah, sexual activity increases his status and solidifies his peer-group bonds, sexual agency could decrease social status for women, and is excluded from peer-group conversation about sex.

Further, the narratives of some male participants illustrate the role that the objectification of women plays in constructing active masculine identities among teenage boys. These male peer group conversations about sex reflect the findings of CJ Pascoes (2007) ethnographic study of high school masculinity, in which she notes the way that masculinity is primarily defined through performances of domination and control among young men. While access to the agency script can celebrated as a positive step in the development of a healthy sexuality for adolescents generally, these male peer group conversations highlight the importance of remaining critical of the content and form of the agency script in this context

The internet as a source of sexual learning adds nuance to the discussion of this agency script. Seeking information about sex online can be seen as a sort of extension of the agency script, as individuals are active participants in the learning process using the internet. Researcher Gustavo Mesch notes that "the web is an excellent example of a medium that people actively use, and they are not exposed by chance but because they select specific sites" (2009:604). For the male participants in this study, most of the sexual information sought online involved viewing pornography, a pattern reflected in the literature mentioned above. It could be argued that this act of seeking pornography is 
directly related to the agency script; the men in this study recount actively searching out pornographic websites in response to their interests and curiosities, and by doing so claim a sort of sexual agency. Eight of the men in this study recount consuming pornography in this active way, and some, like Cameron, sought it out even in opposition to social pressures. Cameron remembers: "Of course I knew my mother hated pornography and made sure you knew that she hated it... you know I knew that. But it wasn't going to stop me." In this account, Cameron feels uninhibited by the pressure from his mother, and consumes pornography of his own accord, taking up the sexual agency script in this example.

In comparison, the agency script and its influence on sexual learning online exhibit a different pattern for both the female and non-heterosexual participants in this study. Instead of using the internet to view pornography in satisfaction of personal sexual drive or desire, five women in this study remember the internet as a tool for learning about sex in a protected and safe environment. As was mentioned earlier in this chapter, the internet presents promise for women who often experience discomfort asking questions about sex in other settings due to social pressures and restrictive norms. The women in this study who found information about their bodies, identities and sexualities online remember this as an active experience, where they sought out information and took up the agency script. Courtney remembers her experience seeking information online:

I started learning more things, not just about biology but about feminism as well. That's when I started--consent was-- just attaching that word to the concept was very new to me even in college. And having a say in what happens to my body. That was pretty much all stuff I learned on the internet. 
In her reflection, Courtney interacts with the agency script by seeking sexual knowledge online, and in being affirmed by an online community who gave her access to information. She notes specifically that this experience was contrary to other places that she learned about sex, indicating that the internet for her was an important avenue for sexual agency. In a similar way, Kevin, a gay participant remembers the internet as an important source of agency for him as well, as he sought out information that affirmed his identity and helped him process his experiences. Kevin remembers: "So the internet was kind of like how I found myself... I ran into and encountered people and I would talk to them. They were like 'oh yeah, I'm gay.' I was like 'oh what's that like?' So I found out a lot about that through personal experiences." Kevin recalls the internet as a place where he actively sought information about his identity, a clear reflection of the agency script. Kevin goes on to describe the internet as "an environment that was more welcoming. There was no one who was going to say 'that's not right."' The experiences of these female and sexual minority participants indicate an important association between sexual learning online and the agency script. In this online space, these participants were able to take up the agency script and actively seek information that helped them explore and affirm their sexual identities and experiences.

\section{Social Consequences Script}

As referenced in the previous chapter, the social consequences script scripts sexuality as having social repercussions for the actor. This script communicates the understanding that being sexual could damage one's reputation, affect social status, and limit prospects for a future mate. In parallel with participants' experiences of school- 
based sex education, the social consequences script was remembered by more female participants than male participants in family conversations about sex. Parents and families are embedded in the cultural understanding that sexuality has more repercussions for their teenage daughters than their teenage sons (Nolin and Petersen 1992), and when talking about sex with their daughters, emphasize the social consequences associated with active female sexuality. Four out of ten women in this study remember being exposed to the social consequences script in their families in comparison with one out of ten men. Molly remembers being warned by her mother of the social implications of pregnancy, a risk implicit in teenage sexual activity. Molly recalls:

Talking with her and the emphasis she put on it only being me, kind of thing. Like she did not want to raise my grandchildren, that just has stuck with me because if I get pregnant--another thing she emphasized and I think is maybe emphasized a lot through TV as well--that when girls get pregnant and you're not married or planning it then the guy--its typical that he runs away, you know? And so it was this concept of if I get pregnant I am all by myself. Even if this person says they would be there with me or whatever I am going to be by myself and then I am going to have to make this decision to either have a child and care for it entirely on my own or make the decision to have an abortion. So those things--I mean those are very severe things that my mom made very clear to me.

The very serious social consequences associated with being sexual are instilled in Molly from this conversation with her mother. For Molly sex was communicated as something that could lead to pregnancy, and eventually to her being left "all by herself". This conception of sexuality, consistent with cultural definitions of female sexuality (Laws and Schwartz 1977) is also present in remembered conversations with peer groups.

As was noted earlier, female peer-group conversations about sex were limited, especially compared with the men in this study, and most women did not consider peers their most important source of sexual information. However, some of these conversations 
about sex had among women focused on the social consequences of sex; three out of ten women in this study recall the social consequences script in conversations about sex with friends, in comparison with no men. Crystal remembers her experience in school, learning that her body could be sexualized and have consequences for her social reputation. Crystal recounts: "I remember getting called a slut when I was really, really young because I started getting boobs in the 3rd grade and of course you know I was wearing my glasses and my head gear with my asthma inhaler around my neck, such a slut. Totally seeing all the action back then." Crystal learns from her peers that sexuality, and having a body that could be sexualized would have social consequences. The policing by peers remembered by Crystal was experienced by other women in this study, like Molly who remembers how she and her friends would talk about female peers whom they saw as sexually deviant. Molly remembers:

And then there were kids, I mean the girls in high school that people labeled as the whores and the sluts and whatnot that have gone out and had sex with several different partners and you kind of wonder like "what's their home life like? What's wrong..." Not what's wrong with them but "why do they feel the need to do this?" was definitely something that I thought about. And kind of a "what the hell?"

In Molly's story, girls who are sexually active are "labeled as the whores and the sluts." As Molly learns about sexuality from her peers, she learns the social consequences her female peers suffer as repercussions of sexual activity, and is exposed to the social consequences script.

\section{Gatekeeping Script}


In combination with learning that sexuality has social consequences and physical risks, women are often encouraged to be defensive sexually (Wiederman 2005). In contrast to men who learn their role as sexual actors, women learn that their role is to fend off sexual advances, a practice termed sexual gatekeeping. In this study, four out of ten female participants remembering being exposed to the gatekeeping script in their families, in comparison with no male participants. Culturally, parents are conscious that the risks of sexuality are many and severe for their daughters, and may be motivated to encourage their daughters to be protective and defensive of sexual encounters. Courtney remembers:

I remember my grandmother telling me when I was a really little kid... "Don't let boys touch you" and I thought she was making a joke or something. Because I was a little kid, I was like "don't let boys touch me? What?" and you know, 10 or 15 years later I was like "oh yeah, she told me. She was right." She knew what she was talking about. If only I had listened [laughs].

Courtney remembers her grandmother encouraging her to be defensive of "boys", and being scripted as a gatekeeper in sexual interactions at a young age. She learns from her grandmother of the potential sexual threats awaiting her in adulthood, and being is advices to be defensive in protection of herself. The gatekeeping script also communicates to women who take it up that they are responsible for setting boundaries in sexual relationships. Kelsey remembers her dad's advice:

I'm sure we even had pamphlets on dating older boys because sometimes older boys are more experienced. I found the pamphlet my senior year and my dad told me to keep it because I was going into college and there was a good chance I would be dating older boys there too who would have more experience and it had advice on how to avoid getting pressured.

In her memory Kelsey is encouraged to learn 'how to avoid getting pressured' by her male peers at a college. In this illustration of the gatekeeping script, Kelsey taught to be 
responsible for managing and defending sexual pressure from 'older boys'. In this case and others, parents communicate these messages out of concern for the safety of their daughters, and this gatekeeping script was remembered by several female participants as a central message in their family communication about sex.

Missing an Affirming Script

As was discussed in the previous chapter, lacking sexual scripts that affirm personal identity, interest or desire can leave individuals repressed, conflicted or confused. In their work, sociologists Laws and Schwartz (1977) detail the ways that not having access to scripts can invalidate individual feelings or experiences. Participant accounts reveal that scripts that affirm sexual desire and activity for women were largely missing that school-based sex education. In comparison, informal sources of sex education exhibit some differences, but, as participant accounts indicate, are also missing affirming scripts in some cases.

As was noted in the literature, sons seem to be disadvantaged in comparison with daughters when it comes to parent-child communication about sex. This conclusion was largely true of the male participants in this study. Wayne's account is an example of this trend:

My mom didn't bring it up until very late. I think I was probably seventeen and it was sort--maybe sixteen? Yeah, it was sixteen. But it was like, there was a kind of tension in even bringing it up where I could tell she didn't feel comfortable... and she--because she had brought it up so late and with kind of this hesitancy like "if there's ever anything you want to.." It felt not really genuine...there would still be like this shame of talking to her about it and asking and you know, she offered like "if you ever need contraceptives or to go to the doctor let me know." But I was like "I am never going to ask my mom to buy me that stuff." 
In Wayne's memory he recalls a lack of conversation with his mother about sex and sexual experience, and calls the conversation that they did eventually have hesitant, uncomfortable and shameful. Wayne, and many of the men in this study remember feeling like talking to parents about sex would be awkward and uncomfortable, and they note their parent's general avoidance of these conversations. Missing this sexual learning at home sometimes meant that these men sought sexual information elsewhere. Wayne goes on to describe his mother's approach: "She maintained kind of a puritanical, like don't talk about it thing. So I didn't, I am sure I heard about sex and its existence form multiple media places before I actually had a discussion about it." In Wayne's case, media sources supplemented his lack of sexual knowledge. Caleb recalls a similar experience. When asked what he learned about sex from his family, he replied: "Very little. Very, very little. Yeah, my parents were never really good at connecting with me on that level. So I would say 99.999 percent repeating came from my own personal experiences and not from my family." Caleb remembers that what he didn't learn about sex from his family, he learned from personal experience in a similar way that Wayne supplemented knowledge with media. The narratives run counter to the experiences of many of the women in this study, who do remember talking with their mothers about sex. Missing this important sources of sexual learning, and access to affirming sexual scripts from their families, these male participants are exposed to sexual scripts in other settings, like the internet or peer groups where traditional masculinity is often reinforced.

Lastly, many female participants recount the absence of an affirming script in their informal sex education experiences, most especially among their peers. Five of the women in this study recall discomfort and hesitancy in conversation about sex with their 
friends, and this likely resulted in a significant knowledge gap in comparison with their male peers who talked more openly about sex. Courtney recalls the way these restricted and awkward conversations went between her and her female friends:

It was always sort of like an indirect kind of thing. No one was like "hey this is what this is." It's like you know, you make a joke about something and you just sort of pick up what's implied from that joke, that sort of thing... it was just really like jokey, like it's something to laugh about not really something to ever take seriously.

Courtney's narrative that describes sex talk among her peers as hesitant and restrained is in striking contrast to the conversations remembered by many male participants, who recall the detailed retelling of sexual experiences and the open sharing of pornography. In another example of this absence of open conversation, Taylor remembers the lack of sexual knowledge among her female peers:

They had no fucking idea what was going on. Together as a group we knew basics, obviously. With the pictures and the STIs and STDs but we didn't know anything else. And it was interesting because during recess the boys would talk about it all the time...And yeah, but no. They had no idea. As a whole group we didn't know.

In Taylor's memory she compares her female friends and their lack of conversation about sex to the boys at school, who talk about sex 'all the time'. This knowledge gap means these girls have little information about sex, especially in comparison with their male peers. This lack of communication about sex could be the result of sanctioning of sexual curiosity of interest in sex is in line with traditional norms that describe female sexuality as passive and absent of embodied desire (Tolman 2002). In these limited conversations, women have little access to scripts that would have affirmed their sexual feelings or experiences, and are instead left missing a script. 


\section{Discussion}

Drawing on participants accounts, the sexual scripts identified through experiences with school-based sex education have been found to persist in conversations about sex in the family and in peer-groups. However, families and peer-groups are less controlled settings than the sex education classroom and gendered patterns of communication shape the ways that sexual scripts are made available in these more informal settings. Narratives in this study support previous literature finding that daughters hear more about sex than do sons, especially from their mothers. Peer-groups prove to play a much bigger role in sexual learning for teenage boys than for teenage girls, a pattern demonstrated through participant's accounts in this study. Lastly, the internet is an expanding source of sexual knowledge for teenagers, although internet use differs by gender. All male participants in this study report using the internet to access pornography, and many communicate about pornography consumption in their peer groups. This dynamic is in contrast to the internet usage of female participants, none of whom recalled seeking pornography online, but rather remember tension and embarrassment linked to internet searches about their sexualities. Lastly, several narratives in this study support the optimistic prediction that the internet could become a place for women to have access to sexual knowledge in private and without social stigma (Leiblum 2001).

The agency and desire scripts that were made available to men during schoolbased sex education had more nuance in the family and peer groups. The desire script, that affirms sexual feelings and interest, was still remembered almost entirely by male 
participants in family and peer-group conversations about sex. The agency script, that describes an individual as a sexual actor, capable of their sexual decision making, was a dominant theme among male peer-group communication about sex as they performed their sexual interest and experience as a part of constructing masculine identities. For female participants, the agency script was entirely missing from conversations with friends, but was foundational in mother-daughter talks about sex. This finding suggests an important generational shift for women, as mothers who suffered the power imbalances of adult gendered sexuality try to empower their daughters.

The danger script, that emphasizes teenage sexuality as irresponsible and physically dangerous is recalled by both men and women in conversations with families in this study. Interestingly, while male participants were presented with this danger script in both school-based sex education and in their families, some men constructed a counter risk taking script in their peer groups that was more compatible with dominant cultural masculine scripts. These men rejected messages about safe sex and respect as a way of embracing sexual risks and achieving masculinity, a conclusion similar to previous work on the subject (Noar and Morokoff 2002).

The social consequences and gatekeeping scripts that warn the individual of the social repercussion of sexuality and subsequently encourage them to be sexually defensive remain feminized in communication about sex from family and peers. Female participants remember hearing from their families about the social cost of pregnancy and learning about the decrease in status associated with active female sexuality or sexual interest from their friends. The gatekeeping script was reemphasized in the family setting for women, as they were encouraged to be alert, aware and defensive about sexual 
advances from their male peers. Both male and female participants alike were found to be missing affirming scripts in their more informal sex education experiences. Many men in this study lacked substantive conversations about sex in their families, and did not have access to scripts communicated in that setting. In comparison, female participants recalled little to no sexual learning among their friends and missed affirming sexual scripts communicated in peer groups.

Using sexual script theory (Gagnon and Simon 1973) as a framework, the narratives of the participants in this study illustrate the ways that family and peer-groups play important parts in the sexual socialization of adolescents as they transition into adult sexuality. Through this analysis, persistent sexual scripts that affirm male desire and agency can be seen as problematic in the way that they combine with messages embedded in school-based sex education to reproduce cultural power dynamics expressed in adult masculinity. Women learn through the sexual scripts made available to them by their families and peer groups, and reinforced in sex education programs that their sexualities have consequences, repercussions and dangers and that their sexual exploration should be limited. However, the agency script made available to female participants through mother-daughter communication and the emergence of online resources are hopeful conclusions for women, pointing towards possible shifts in cultural conceptions of female sexuality. These findings point to utility of sexual script as a tool with which to identify gendered sexual messages transmitted through cultural institutions. 


\section{CHAPTER 6: CONCLUSION}

Drawing on participants' accounts, I argue that the different sexual scripts made available to men and women from both formal and informal sources of sexual learning play a central role in perpetuating traditional masculine and feminine sexual norms. Inherent in these norms, reproduced by these differential sexual scripts, is the sexual double standard that rewards sexual behavior for men, while penalizing and sanctioning sexual desire, interest and behavior among women. If scripts can be compared with blueprints that guide sexual behavior and assign different roles to sexual actors, then the blueprint for sexuality remembered generally by the women in this study scripted sex as dangerous and rife with social consequences. In comparison, many of the men in this study recall learning scripts that scripted them as sexual actors, rewarded for their sexual desire and sexual risk taking. While potentially disheartening, these findings are not necessarily surprising; as the sex education classroom is embedded in our current social context, we can expect to see dominant conceptions of masculine and feminine sexuality reflected there. However, understanding and isolating the role that sex education plays in the perpetuation of these norms, or scripts, is important, especially for the project of gender equality.

The sexual scripts communicated in formal and informal sources of sex education exhibit many similarities, but also a few notable differences. While the risk-taking script is constructed in male peer groups, affirming some aspects of traditional masculine sexuality, a more optimistic conclusion follows: many female participants report access to the agency script in communication about sex with their mothers. Personal motivations for these conversations based on the agency script indicate a generational shift towards 
more support and affirmation of sexual experience and interest for adolescent girls. Additionally, sexual learning online exhibits important potential for women, who recount increased access to information that affirmed their sexuality and sense of sexual agency via the internet.

\section{Findings}

The first analysis chapter explored the sex education classroom and drew from participants' narratives of learning about sex in school. Participants discussed what they learned about biology and anatomy, sexual desire, abstinence and virginity, and from common themes in these accounts five sexual scripts were developed.

The danger script was defined as communication about sex that emphasized the physical dangers of sex, like STD acquisition or pregnancy. In school-based sex education, this script was heard by roughly equal numbers of men and women, suggesting that this message was meant generally for all adolescents in these sex education programs. It could be expected that the danger script was a prominent theme in participants' memories, as it reflects cultural perceptions about teenage sexuality as a social problem in general, and the idea that school-based sex education is an intervention measure meant to curb or delay 'risky' sexual behavior among teens (Bay-Cheng 2003; Fallon 2013). Several participants claimed that their sex education programs were 'abstinence-only', and described the fear-based danger script as integral to messaging about abstinence.

Important gendered patterns emerged in access to sexual scripts based on gender. More men than women recalled the affirming desire script in their accounts of school 
based sex education. Again, we see the framework for traditional masculine sexuality being constructed through access to this script, as men learn that their sexual desire is normal and innate, not something 'to be scared of.' Without access to this script, women are understood as lacking embodied sexual desire and some women in this study described feelings of confusion and emotional discomfort, as they tried to understand their feelings and experiences without an affirming desire script. In another example of this gendered pattern, the agency script was remembered by more men than women in school-based sex education. This finding outlines the role that sex education plays in constructing and reproducing a sexual double standard for men and women. For the men who remembered hearing and having access to this script, they were affirmed in their role as actors in a sexual encounter. A passive and defensive role is scripted for women, laying the foundation for the gendered binary of sexual experience dominant in cultural understandings of sex and sexuality.

Scripts remembered by more women than men include the social consequences script and the gatekeeping script. The social consequences script was remembered by a majority of the women in this study; access to this script illustrates the ways that traditional feminine sexuality is constructed and enforced in school-based sex education. As a compliment to masculine sexual norms, this social consequences script enforces the sexual double standard by normalizing the consequences sexually active women face, like being labeled a 'slut,' or social exclusion. In line with this gendered pattern, more women than men remember hearing the gatekeeping script in school-based sex education. A clear extension of the social consequences script that warned women of the hazards of sexuality, the gatekeeping script indicates that, because sex is relatively high-risk for 
women, it is a woman's responsibility to regulate a sexual encounter. This dynamic is reflected in dominant understandings of masculine and feminine sexuality, and has particularly insidious consequences. These different sexual scripts can potentially normalize aggressive and defensive sexuality and may foster instances of sexual coercion and assault.

The second analysis chapter explored more informal sources of sexual learning like the family, peer groups and the internet, in comparison with school-based sex education. The same sexual scripts were revisited, and nuances in communication and access to scripts were discussed. Additionally, a counterscript that developed among peer groups was introduced.

Gendered patterns in the structure of communication between children and parents, and among adolescents in peer groups were noted, as the findings in this study were consistent with previous documentation. In families, it is important to note that daughters hear much more about sex than do sons. An explanation for this might be that children and parents feel more comfort when talking about sex in same-gender pairs, mothers with daughter and fathers with sons, and mothers tend to do most sex educating in families in general. This means that sons lose out when learning about sex from the family, and the male participants in this study had fewer conversations about sex with parents in general, especially in comparison with female participants. Most women in this study recall conversations with their mothers specifically about sex, and count their mothers as safe and trusted sources of sexual learning.

While men learn less about sex from their families, they make up for this knowledge gap with communication about sex in peer groups. Men talk more openly and 
extensively about sex with friends than do women, and often use peer groups as audiences for displays of masculine (hetero) sexuality. Most men in this study remember extensive and in-depth sex talk among friends, and remember the sharing and discussing of pornography, recounting sexual experiences, and sexualizing their female peers in these groups. In contrast few women in this study recount talking about sex with their peers in adolescence. Sex seemed a taboo subject, and some women remember not wanting to seem overly interested in or curious about sex. The limited conversations about sex that were remembered by female participants often consisted of policing their female peers, expressing disapproval, pity or concern for the girls they knew who were sexually active.

With these gendered patterns in mind, the sexual scripts developed in the first chapter were revisited. Some of the findings from the first chapter were reaffirmed. The danger script, emphasizing the physical dangers of sex was remembered by both men and women in conversations with their families. The danger script played a limited role in peer group conversations, however. This is understandable, as parents are tasked with protecting their children from the dangers of sex; therefore warnings about STDs and pregnancy would be dominant themes in the conversations they initiate about sex. In peer groups, talk about physical dangers might not be desirable, as these friend groups are spaces for playful curiosity and exploration, especially for men.

Drawn from male participants' accounts of these peer group conversations about sex, a counterscript was constructed in opposition to the danger script. While men remember hearing messages about the dangers of sex in school-based sex education and from their families, some of them constructed a counterscript, the risk-taking script that 
described sexual risk taking as adventurous and masculine. These men remember communication about sex that affirmed risk taking and encouraged boundary pushing in sexual encounters. The desire script is remembered by more men than women in both the family and in peer groups, a reflection of access to this script in school-based sex education. Understandings about masculine sexuality as inherently desirous seemed to bleed into family conversations about sex, and played a central role in peer group communication for men. Most male participants remember learning about and demonstrating their (hetero) sexual desire as an important tool for bonding and inclusion in male peer groups. As an extension of this, the agency script was remembered by a majority of male participants in peer group conversations about sex, a reflection of their interaction with this script in school-based sex education. As they shared sexual stories, they communicated and took up this agency script, affirming their role as the actor in a sexual scenario. While access to the agency script can be seen as a step in the process of health identity formation in adolescence, some of the narratives of male participants in this study indicate the need to remain critical of the form this script takes in male peer groups, as this often involves the objectification and subordination of women.

For the women in this study, access to the social consequences script followed a similar pattern in the family and in peer groups. Women recall hearing this script from their families, as well as from their peers, in comparison with fewer men. This trend mirrors interaction with the social consequences script in school-based sex education, indicating that access to this script reinforces dominant norms regarding feminine sexuality. In accordance with this pattern, the gatekeeping script was also recalled by women, especially in communication about sex from their families. While none of the 
female participants in this study recall hearing this script in communication with friends, mirroring their experiences in school-based programs, an important comparison emerged when these women recalled conversations about sex they had with their mothers while growing up. In an interesting twist, half of the women in this study remember hearing the agency script from their mothers. In these conversations they remember learning that they were sexual beings, capable of their own sexual decision making. Interestingly, the motivation for this sort of conversation could indicate a generational shift in access to the agency script; many of these female participants recall that their mothers indicated a desire to give their daughters better communication about sex than they themselves had. This important finding points to a positive shift in traditional conceptions of feminine sexuality, as more mothers give their daughters access to this agency script.

Lastly, this agency script had an interesting association with sexual learning online. While men and women sought out different sexual content on the internet, this act of actively seeking information to affirm sexual interest or identity can be thought of as a taking up of the agency script. For men, this meant seeking pornography, while for the women in this study this often resulted in access to affirming messages about sexuality, or gaining important information needed for sexual empowerment. This finding hints at potential shifts in conceptions of feminine sexuality, as more women gain access to scripts online that increase their sense of sexual subjectivity.

Formal and Informal Sex Education

The findings of the first analysis chapter indicate that formal school-based sex education represents relatively controlled settings where students are taught about sex by 
an appointed teacher using defined curricula. In this setting, dominant social messages about sex and gender are reproduced, demonstrating the way that the sex education classroom is an institution deeply embedded in our current cultural context, influenced by societal norms. The sexual scripts remembered by participants from their experiences with school-based sex education are the framework for traditional, gendered sexuality, and differential access to these scripts based on gender has the potential to reproduce a sexual double standard inherent in adult, gendered sexuality.

In comparison, informal sources of sex education proved to be much more dynamic and less controlled. Families and peer groups are participatory and interactional, and the sexual scripts communicated there have the potential to either reemphasize traditional conceptions of sexuality, or challenge them. Peer groups are especially dynamic, and the experiences of some male participants demonstrate the potential that peers have to collectively construct new scripts among themselves, scripts that run counter to messages learned in other settings. Families are certainly influenced by social norms, but the experiences of several female participants in this study indicate that they can also be settings that are more sheltered from dominant conceptions of gendered sexuality. In their families, these female participants experienced interaction with affirming sexual scripts not allowed them in more controlled, public settings like schoolbased sex education. Online sexual learning also held promise for women as a source of information necessary for the development of sexual subjectivity. These findings point to the family and the internet as potential sites of social change, especially for women. Increased access to sexuality on the internet and generational shifts in family communication about sex both hint at new conceptions of female sexuality, and 
increasingly equal access to affirming sexual scripts on the horizon. These informal sources of sex education offering access to affirming scripts for the women in this study are more responsive to social changes and more dynamic in comparison with the rigid framework of school-based sex education. The findings of this study indicate that dominant norms are consistently reproduced through school-based programs, allowing the majority of women access only to scripts that reinforce traditional feminine sexuality. In comparison, informal sources of sex education serve the needs of women best, and allow access to the agency and desire scripts foundational to sexual subjectivity.

The findings in this study shed light on the role that school-based sex education, and other more informal sources of sexual learning play in constructing, reproducing, enforcing and challenging the sexual double standard that is dependent on different norms for masculine and feminine sexual behavior. However, a few nuances suggest avenues for possible social change. These findings have several implications, both practical and theoretical.

\section{Implications for Policy and Practice}

In Michelle Fine's (1988) formative study on sex education the author concludes that there is a 'missing discourse' of desire in school-based programs, and argues these programs that limit discussion of sex to its dangers and consequences are particularly harmful to women, who are most often described as the victims of sexual dangers. These discourses have been found to limit female sexual subjectivity, a concept similar to the agency script described in this study. In her conclusions, Fine (1988) calls for public schools to acknowledge the "fullness of female subjectivities" (pg. 41). Fine offers 
several practical suggestions which this research supports, such as increased access to contraceptive options and education for informed sexual decision making. If these resources are offered to young women without social stigma or required adult consent, sexual agency is allowed that can be formative in constructing a "sexual subjectivity". These resources, along with open conversation about these resources as choices possible for young women to make, could constitute a framework for access to the agency script, largely absent from female participants' narratives in this study.

Practical solutions cannot be suggested without acknowledging the theoretical implications foundational to this study. While resources and education are important responses to the problem of inequality, especially for the individual teenage girl, this study documents the salience of gendered sexual norms, or scripts, and the central role they play in the organization of social sexuality. The look forward offered by this study regards the ways that society is reconsidering traditional femininity and is beginning to acknowledge the ways that women are disadvantaged by this limiting identity. The words of participants' mothers illustrate a general shift on the horizon for social understandings of feminine sexuality, and indicate an interest in improving the social role available to women. However, as sociologist Emily Kane (2012) concludes in her study of gender and parenting, this recent cultural trend of re-evaluating traditional femininity and its utility for girls may not necessarily imply an impending re-evaluation of traditional masculinity. In her study, many of Kane's participants encourage their daughters to pursue more masculine career paths, interests or character traits, and while this looks on the surface to be the beginnings of social change, Kane equates this redefinition of femininity instead to a devaluating of the feminine, in "fundamentally the same way as hegemonic masculinity 
does more explicitly" (2012:203). Kane's (2012) conclusion indicates that a re-evaluation of traditional masculinity is necessary for any meaningful social change; in contrast, participant accounts in this study illustrate the ways that masculine sexuality is learned and reinforced consistently in school, in families and in peer groups. In this way, the findings of this study shed light on deeply entrenched gendered sexual norms that must be called into question not only in a practical manner to better the lives of individual young girls, but also in a more abstract way that challenges the binary structure relied upon for our organization of social sexuality.

This conclusion is reflective of sociologist Paula England's conception of the "unequal gender revolution" (2010:149). In her work, England (2010) argues that social life has changed much for women over time, as they are increasingly incentivized to move into more masculine careers and spheres of social life. This gender revolution is uneven however, because traditionally feminine domain is still devalued in society, and men remain reluctant to embrace feminized careers and activities. England writes that "social incentives themselves flow from a largely unchanged devaluation of things culturally defined as feminine. When boys and men take on 'female' activities, they often suffer disrespect..." (2010:156). The framework of this unequal gender revolution can be seen in the findings of this study, with female participants in some cases gaining access to and embracing aspects of traditionally masculine sexuality, like sexual agency and affirmed sexual desire, and male participants instead recounting very few experiences with social change in learning about sex. The gender revolution, put in terms of gendered access to sexual scripts, remains uneven and stalled in the accounts of participants' sex education experiences. 
With this in mind, documentation of sexual scripts in sex education and how access to them varies by gender is also a useful tool when thinking about policies regarding sexual assault. In the summer of 2014, California voters passed a so-called "yes means yes" law, that requires universities to consider the presence of affirmative consent when evaluating sexual assault charges (http://www.leginfo.ca.gov/). While an important attempt at preventing campus sexual assaults, this study implies that the application of such a policy would require a fundamental shift in the sexual scripts made available to men and women in adolescence, scripting one party as aggressive and the other defensive in a given sexual encounter. The scripting approach, in light of the findings of this study, offers important social insights regarding the implementation of policies meant to address real world problems.

\section{Conclusion}

Sexual scripts offer an important analytical tool for understanding the different masculine and feminine sexual norms that have influence individual men's and women's behavior and relationships. As remembered by participants in this study, the sex education classroom is a setting where scripts are learned, and is reflective of dominant cultural conceptions of the sexuality appropriate for men and women. The sexual scripts drawn from participant interviews allow for the particular role that school-based sex education plays in reproducing the sexual double standard to be isolated and analyzed, offering important information for the debate around sex education programs generally, and the policies that affect students. In comparison, participant experiences of learning 
about sex from more informal sources demonstrate the salience of these sexual scripts, but also indicate a few important nuances.

The conclusions of this study hope to contribute understandings of gendered sexuality as constructed and learned through social institutions, and to highlight the ways that this system further reproduces a sexual double standard and, ultimately, gender inequality. Additionally, these findings argue that informal sources of sexual learning like families and the internet should be held up as having special potential for combating this gendered organization of social sexuality. 


\section{REFERENCES}

Albury, Kath. 2014. "Porn and Sex Education, Porn as Sex Education." Porn Studies 1(12): $172-181$.

Alexander, Michele G., and Terri D. Fisher. 2003. "Truth and Consequences: Using the Bogus Pipeline to Examine Sex Differences in Self-reported Sexuality." Journal of Sex Research 40(1):27-35.

Allen, Louisa. 2006. "“Looking at the Real Thing": Young Men, Pornography, and Sexuality Education." Discourse: Studies in the Cultural Politics of Education 27(1): 69-83.

Anderson, Eric. 2008. "Inclusive Masculinity in a Fraternal Setting." Men and Masculinities 10(5): 604-620.

Arendell, Terry. 1997. "Reflections on the Researcher-researched Relationship: A Woman Interviewing Men." Qualitative Sociology 20(3): 341-368.

Bay-Cheng, Laina Y. 2003. "The Trouble of Teen Sex: The Construction of Adolescent Sexuality through School-based Sexuality Education." Sex Education: Sexuality, Society and Learning 3(1): 61-74.

Bleakley, Amy, Michael Hennessy, Martin Fishbein, and Amy Jordan. 2009. "How Sources of Sexual Information Relate to Adolescents' Beliefs about Sex." American Journal of Health Behavior 33(1): 37.

Bowleg, Lisa, Kenya J. Lucas, and Jeanne M. Tschann. 2004. "“The Ball was Always in His Court": An Exploratory Analysis of Relationship Scripts, Sexual Scripts, and Condom Use among African American Women." 2004. Psychology of Women Quarterly 28(1): 70-82.

Brickell, Chris. 2006. "The Sociological Construction of Gender and Sexuality." The Sociological Review 54(1): 87-113.

Byers, E. Sandra. 1996. "How Well Does the Traditional Sexual Script Explain Sexual Coercion? Review of a Program of Research." Journal of Psychology \& Human Sexuality 8(1-2): 7-25.

Carpenter, Laura M. 1998. "From Girls into Women: Scripts for Sexuality and Romance in Seventeen Magazine, 1974-1994." Journal of Sex Research 35(2): 158-168.

Carpenter, Laura M. 2005. Virginity Lost: An Intimate Portrait of First Sexual Experiences. NYU Press.

Carpenter, Laura M. 2009. "Virginity Loss in Reel/Real Life: Using Popular Movies to Navigate Sexual Initiation1." Sociological Forum. 24(4).

Chambers, Deborah, Estella Tincknell, and Joost Van Loon. 2004. "Peer Regulation of Teenage Sexual Identities." Gender and Education 16(3): 397-415.

Charmaz, Kathy. 2006. Constructing Grounded Theory: A Practical Guide through Qualitative Analysis. Sage.

Choo, Hae Yeon, and Myra Marx Ferree. 2010. "Practicing Intersectionality in Sociological Research: A Critical Analysis of Inclusions, Interactions, and Institutions in the Study of Inequalities*." Sociological theory 28(2): 129-149.

Connell, R. W. 1983. Which Way is Up?: Essays on Sex, Class, and Culture. Allen \& Unwin Academic. 
Connell, R.W., and James W. Messerschmidt. 2005. "Hegemonic Masculinity Rethinking the Concept." Gender \& society 19(6): 829-859.

Cornblatt, Johannah. 2009. "The Sin of Yielding to Impure Desire: A Brief History of Sex Ed in America. Newsweek."

De Beauvoir, Simone. 1949 "The Second Sex." Trans \& Ed. HM Parshley

de Boise, Sam. "I'm Not Homophobic, I've Got Gay Friends" Evaluating the Validity of Inclusive Masculinity." 2014. Men and Masculinities. 1-22.

Döring, Nicola M. 2009. "The Internet's Impact on Sexuality: A Critical Review of 15 Years of Research." Computers in Human Behavior 25(5): 1089-1101.

Eberwein, Robert T. 1999. Sex Ed: Film, Video, and the Framework of Desire. Rutgers University Press.

Elia, John P., and Mickey J. Eliason. 2010. "Dangerous Omissions: Abstinence-onlyuntil-marriage school-based Sexuality Education and the Betrayal of LGBTQ Youth." American Journal of Sexuality Education 5(1): 17-35.

Elliott, Sinikka. 2012. Not My Kid: What Parents Believe About The Sex Lives Of Their Teenagers. NYU Press.

England, Paula. 2010. "The Gender Revolution Uneven and Stalled." Gender \& Society 24(2): 149-166.

Epstein, Marina, and L. Monique Ward. 2008. "“Always Use Protection": Communication Boys Receive about Sex from Parents, Peers, and the Media." Journal of Youth and Adolescence 37(2): 113-126.

Fagen, Jennifer Lara, and Peter B. Anderson. 2012."Constructing Masculinity in Response to Women's Sexual Advances." Archives of Sexual Behavior 41(1): 261-270.

Fallon, Debbie. 2013. "'They're Gonna Think it Now': Narratives of Shame in the Sexual Health Experiences of Young People." Sociology 47(2): 318-332.

Fields, Jessica. 2008. Risky Lessons: Sex Education and Social Inequality. Rutgers University Press.

Fine, Michelle. 1988. "Sexuality, Schooling, and Adolescent Females: The Missing Discourse of Desire." Harvard Educational Review 58(1): 29-54.

Fisher, Christopher Micheal. 2009. "Queer Youth Experiences with Abstinence-OnlyUntil-Marriage Sexuality Education:"I can't get married so where does that leave me?"." Journal of LGBT Youth 6(1): 61-79.

Flood, Michael. 2008. "Men, Sex, and Homosociality How Bonds between Men Shape Their Sexual Relations with Women." Men and Masculinities 10(3): 339-359.

Gagnon, John H. 1990. "The Explicit and Implicit use of the Scripting Perspective in Sex Research." Annual Review of Sex Research 1(1): 1-43.

Gagnon, John H., and William Simon. 1973. Sexual Conduct: The Social Origins of Human Sexuality. Chicago: Aldine.

Gailey, Jeannine A., and Ariane Prohaska. 2011. "Power and Gender Negotiations during Interviews with Men about Sex and Sexually Degrading Practices." Qualitative Research 11(4): 365-380.

Gates, Gary J. 2006."Same-sex couples and the gay, lesbian, bisexual population: New estimates from the American Community Survey." The Williams Institute (2006). 
Gordon, Liahna E., and Lyndall Ellingson. 2006. "In the Eyes of the Beholder: Student Interpretations of Sexuality Lessons." Sex Education 6(3): 251-264.

Hald, Gert Martin. 2006. "Gender Differences in Pornography Consumption among Young Heterosexual Danish Adults." Archives of Sexual Behavior 35(5): 577585 .

Hartley, Heather, and Tricia Drew. 2002. "Gendered Messages in Sex Ed films: Trends and Implications for Female Sexual Problems." Women \& Therapy 24(1-2): 133146.

Haste, Polly 2013. "Sex Education and Masculinity: the 'Problem' of Boys". Gender and Education 25(4): 515.

Hynie, Michaela, et al. 1998. "Relational Sexual Scripts and Women's Condom Use: The Importance of Internalized Norms." Journal of Sex Research 35(4): 370-380.

Hutchinson, M. Katherine, and Teresa M. Cooney. 1998. "Patterns of Parent-teen Sexual Risk Communication: Implications for Intervention." Family Relations 185-194.

Hutchinson, M. Katherine, John B. Jemmott, Loretta Sweet Jemmott, Paula Braverman, and Geoffrey T. Fong. 2003. "The Role of Mother-Daughter Sexual Risk Communication in Reducing Sexual Risk Behaviors among Urban Adolescent Females: A Prospective Study." Journal of adolescent health 33(2): 98-107.

Irvine, Janice M. 2004. Talk about sex: The battles over sex education in the United States. Univ of California Press.

Jaccard, James, Patricia J. Dittus, and Vivian V. Gordon. 2000. "Parent-Teen Communication about Premarital Sex Factors Associated With the Extent of Communication." Journal of Adolescent Research 15(2): 187-208.

Jackson, Stevi. 2007."The Sexual Self in Late Modernity." The Sexual Self: The Construction of Sexual Scripts 3-15.

Jackson, Susan M., and Fiona Cram. 2003. "Disrupting the Sexual Double Standard: Young Women's Talk about Heterosexuality." British Journal of Social Psychology 42(1): 113-127.

Kane, Emily W. 2012. The Gender Trap: Parents and the Pitfalls of Raising Boys and Girls. NYU Press.

Kehily, Mary. 2001. "Bodies in School Young Men, Embodiment, and Heterosexual Masculinities." Men and Masculinities 4(2): 173-185.

Kelly, Maura. 2010. "Virginity Loss Narratives in" Teen Drama" Television Programs." Journal of Sex Research 47(5): 479-489.

Kimmel, Michael S., ed. 2007. The Sexual Self: The Construction of Sexual Scripts. Vanderbilt University Press.

Kirby, Douglas. 2002. "Effective Approaches to Reducing Adolescent Unprotected Sex, Pregnancy, and Childbearing." Journal of Sex Research 39(1): 51-57.

Kirby, Douglas B. 2008. "The impact of abstinence and comprehensive sex and STD/HIV education programs on adolescent sexual behavior." Sexuality Research \& Social Policy 5(3): 18-27.

Krahé, Barbara, Steffen Bieneck, and Renate Scheinberger-Olwig. 2007. "The Role of Sexual Scripts in Sexual Aggression and Victimization." Archives of Sexual Behavior 36(5): 687-701. 
Landry, David J., Jacqueline E. Darroch, Susheela Singh, and Jenny Higgins. 2003

"Factors Associated with the Content of Sex Education in US Public Secondary

Schools." Perspectives on Sexual and Reproductive Health 35(6): 261-262.

Lucariello, Joan M., and Catherine Mindolovich. 2002. "The Best Laid Plans...: Beyond

Scripts are Counterscripts." Journal of Cognition and Development 3(1): 91-115.

Laws, Judith Long, and Pepper Schwartz. 1977. Sexual Scripts: The social construction of female sexuality. Harcourt College Pub.

Leiblum, Sandra Risa. 2001. "Women, Sex and the Internet." Sexual and Relationship Therapy 16(4): 389-405.

Luker, Kristin. 2007. When Sex Goes to School: Warring Views on Sex--and Sex Education--since the Sixties. WW Norton \& Company.

Marshall, Barbara L. 2006. "The New Virility: Viagra, Male Aging and Sexual Function." Sexualities 9(3): 345-362.

Maticka-Tyndale, Eleanor, et al. 2005 "The Sexual Scripts of Kenyan Young People and HIV Prevention." Culture, Health \& Sexuality 7(1): 27-41.

McCabe, Janice, Amanda E. Tanner, and Julia R. Heiman. 2010. "The Impact of Gender Expectations on Meanings of Sex and Sexuality: Results from a Cognitive Interview Study." Sex Roles 62(3-4): 252-263.

McKee, Alan. 2007. "'Saying You've Been at Dad's Porn Book is Part of Growing up': Youth, Pornography and Education." Metro Magazine 2007(155): 118-122.

McNeill, Tanya. 2013. "Sex Education and the Promotion of Heteronormativity." Sexualities 16(7): 826-846.

Mesch, Gustavo S. 2009. "Social Bonds and Internet Pornographic Exposure among Adolescents." Journal of Adolescence 32(3): 601-618.

Messner, Michael A. 1992. Power at Play: Sports and the Problem of Masculinity. Beacon Press.

Michael, Robert T, John H. Gagnon, Edward O. Laumann, and Gina Kolata. 1994. Sex in America: A Definitive Survey. Boston: Little, Brown.

Mosher, Donald L., and Silvan S. Tomkins. 1988. "Scripting the Macho Man: Hypermasculine Socialization and Enculturation." Journal of Sex Research 25(1): 60-84.

Muehlenhard, Charlene L., and Lisa C. Hollabaugh. 1988. "Do Women Sometimes Say No When They Mean Yes? The Prevalence and Correlates of Women's Token Resistance to Sex." Journal of Personality and Social Psychology 54(5): 872.

Murnen, Sarah K., Carrie Wright, and Gretchen Kaluzny. 2002. "If "Boys Will be Boys," Then Girls Will be Victims? A Meta-analytic Review of the Research that Relates Masculine Ideology to Sexual Aggression." Sex Roles 46(11-12): 359-375.

National Public Radio/Kaiser Family Foundation/Kennedy School of Government. 2004. "Sex Education in America: General Public/Parents Survey." [Washington, DC]: National Public Radio.

Noar, Seth M., and Patricia J. Morokoff. 2002. "The Relationship between Masculinity Ideology, Condom Attitudes, and Condom Use Stage of Change: A structural equation modeling approach." International Journal of Men's Health 1.1 (2002): 43-58. 
Nolin, Mary Jo, and Karen Kay Petersen. 1992. "Gender Differences in Parent-Child Communication about Sexuality An Exploratory Study." Journal of Adolescent Research 7(1): 59-79.

Orbuch, Terri L. 1997. "People's Accounts Count: The Sociology of Accounts." Annual Review of Sociology 23(1): 455-478.

Parker, Richard. 2010. "Reinventing Sexual Scripts: Sexuality and Social Change in the Twenty-First Century (The 2008 John H. Gagnon Distinguished Lecture on Sexuality, Modernity and Change)." Sexuality Research and Social Policy 7(1): 58-66.

Pascoe, C J. 2007. Dude, You're a Fag: Masculinity and Sexuality in High School. University of California Press.

Pini, Barbara. 2005. "Interviewing Men Gender and the Collection and Interpretation of Qualitative Data." Journal of Sociology 41(2): 201-216.

Plummer, Ken. 2005. "Male Sexualities." Handbook of Studies on Men and Masculinities 178-193.

Portland State University. 2014. "Let Knowledge Serve the City." Retrieved June 10, 2014 (http://www.pdx.edu).

Sakaluk, John K., et al. 2014. "Dominant Heterosexual Sexual Scripts in Emerging Adulthood: Conceptualization and Measurement." The Journal of Sex Research 51(5): 516-531.

Sanders, Teela. 2008. "Male Sexual Scripts Intimacy, Sexuality and Pleasure in the Purchase of Commercial Sex." Sociology 42(3): 400-417.

Schalet, Amy T. 2011. Not Under My Roof: Parents, Teens, and the Culture of Sex. University of Chicago Press.

Schneider, Beth E., and Nancy E. Stoller, eds. 1995. Women Resisting AIDS: Feminist Strategies of Empowerment. Temple University Press.

Schwalbe, Michael, and Michelle Wolkomir. 2001. "The Masculine Self as Problem and Resource in Interview Studies of Men." Men and Masculinities 4(1): 90-103.

Scully, Diana, and Pauline Bart. 1973. "A Funny Thing Happened on the Way to the Orifice: Women in Gynecology Textbooks." American Journal of Sociology. 78(4): 1045-1050.

Seal, David Wyatt, and Anke A. Ehrhardt. 2003. "Masculinity and Urban Men: Perceived Scripts for Courtship, Romantic, and Sexual Interactions with Women." Culture, Health \& Sexuality 5(4): 295-319.

Shartshall, Ronny A., John S. Santelli and Jennifer S. Hirsh. 2007 "Sex Education and Sexual Socialization: Roles for Educators and Parents." Perspectives on Sexual and Reproductive Health 39(2).

Shimizu, Celine Parrenas. 2006. "Queens of Anal, Double, Triple, and the Gang Bang: Producing Asian/American Feminism in Pornography." Yale JL \& Feminism 18: 235.

SIECUS. 2007. “Oregon State Profile Fiscal Year 2007.” Retrieved February 25, 2015 (http://www.siecus.org/index.cfm? fuseaction=Page.viewPage\&parentID=487\&gr andparentID $=478 \&$ page $I d=855$ )

SIECUS. 2010. "A History of Federal Funding for Abstinence-Only-Until-Marriage Programs.” Retrieved February 25, 2015 
(http://www.siecus.org/index.cfm?fuseaction=page.viewpage\&pageid=1340\&nod eid=1)

Simon, William, and John H. Gagnon. 1999. "Sexual scripts." Culture, society and sexuality: A reader 29-38.

Sneed, Carl D. 2008. "Parent-adolescent Communication about Sex: The Impact of Content and Comfort on Adolescent Sexual Behavior." Journal of HIV/AIDS Prevention in Children \& Youth 9(1): 70-83.

Somers, Cheryl L., and Amy T. Surmann. 2005. "Sources and Timing of Sex Education: Relations with American Adolescent Sexual Attitudes and Behavior." Educational Review 57(1): 37-54.

Štulhofer, Aleksandar, Vesna Buško, and Ivan Landripet. 2010. "Pornography, Sexual Socialization, and Satisfaction among Young Men." Archives of Sexual Behavior 39(1): 168-178.

Thorne, Barrie. 1993. "Gender play: Boys and girls in school." Gender play: Boys and girls in School

Tjaden, Patricia G. 1988. "Pornography and Sex Education." Journal of Sex Research 24(1): 208-212.

Tolman, Deborah L. 2002. Dilemmas of Desire: Teenage Girls Talk about Sexuality. Harvard University Press.

Walcott, Christy M., Tiffany Chenneville, and Sarah Tarquini. 2011 "Relationship between Recall of Sex Education and College Students' Sexual Attitudes and Behavior." Psychology in the Schools 48(8): 828-842.

Wentzel, Kathryn R., and Lisa Looney. 2007. "Socialization in school settings." Handbook of socialization: Theory and research 382-403.

Wiederman, Michael W. 2005. "The Gendered Nature of Sexual Scripts." The Family Journal 13(4): 496-502.

Whitaker, Daniel J., and Kim S. Miller. 2000. "Parent-adolescent Discussions about Sex and Condoms Impact on Peer Influences of Sexual Risk Behavior." Journal of Adolescent Research 15(2): 251-273.

Ybarra, Michele L., and Kimberly J. Mitchell. 2005. "Exposure to Internet Pornography among Children and Adolescents: A National Survey." CyberPsychology \& Behavior 8(5): 473-486. 


\section{Appendix: Interview Guide for Participants}

Now I'm going to ask you some questions about your experiences with sex education, it may have been awhile so I don't expect you to remember every detail. I just want to know what you remember from that time in your life.

Tell me a little bit about the schools you attended.

At what point was sex education taught?

Tell me about the structure of your sex education program.

Who taught it?

Was it sex-segregated or coed?

How long was the program?

Was it a part of another class?

How large was the group?

How much of the experience was sitting and listening to the teacher and how much was interactive?

Tell me about what you learned about biology and anatomy.

Were there pictures/ textbooks/ diagrams?

What was said about men's bodies?

What was said about women's bodies?

What of this information did you feel like was most important to you personally?

Tell me about what you learned about being 'sexually responsible'

What was said about contraception?

What was said about STI's?

What was said about pregnancy?

According to your sex education experience, what does a sexually responsible man act like?

According to your sex education experience, what does a sexually responsible woman act like?

What of this information did you feel was most important to you personally?

Tell me what was said about sexual desire.

Was it said about boys, girls or both genders?

Tell me what was said about abstinence.

Was it said about boys, girls or both genders?

Tell me what was said about virginity.

Was it said about boys, girls or both genders?

Was virginity described as a gift, a stigma or a step in a process?

Was there a discussion about same-sex sexuality?

How did you feel about your sex education program? (What kind of emotions did you have during?)

Did you learn things you didn't already know?

If so, what?

Did you have questions that weren't answered? 
If so, what?

What aspect of sex was talked about the most?

What did you feel like was the overall message of your sex education program?

What did sex mean to you at the time of your formal sex education class?

What were your thoughts on same-sex sexuality?

Where/when did you first learn about sex?

What were other sources that you learned about sex from?

Family

Peers

Media

Religious community

The internet

(Where did you learn about same sex sexuality?)

From which sources did you learn the most?

How did learning from these other sources compare to learning about sex in school?

Family

Peers

Media

Religious community

The internet

Have you been in a sexual relationship?

When was your first sexual relationship/experience? (In relation to formal and informal sex education)

Did your sex education prepare you for your first sexual experience?

Has your formal sex education experience been helpful in navigating (useful) your current romantic/sexual relationships?

Has your informal sex education been helpful in navigating your romantic/sexual relationships?

What have you learned about sex and sexuality from your own sexual/romantic relationships?

How has your thinking about sex changed since your formal sex education?

When do you think makes it the right time for someone to lose their virginity?

What are your current thoughts about contraception, STI prevention?

What does a sexually responsible man act like?

What does a sexually responsible woman act like?

What do you believe about men's and women's sexual desire? Is there a difference?

If you could change/improve your sex education program knowing what you know now, what would you change? 